\title{
Recent Advances in RNA Structure Determination by NMR
}

Recent progress in RNA structure determination by nuclear magnetic resonance (NMR) spectroscopy has led to the solution of the structure of a number of new RNA and RNAligand complexes. In addition, recent advances in isotopic labeling and the introduction of through-bond experiments to assign bases and phosphate backbones raise the hope of solving even larger and more complicated structures. The limiting step is still the gathering of a large number of nuclear Overhauser effect (NOE) and torsion restraints. Additional sources of information for the structure determination of larger RNA molecules have recently become available, and it is now possible to supplement NOE and J-coupling data with the measurement of dipolar couplings and cross-correlated relaxation rates in high-resolution NMR spectroscopy. The high quality of current structures of small- to medium-sized RNAs can be examined, and the prospects for solving larger RNA structures to equivalent levels of resolution can be assessed.

The recent proliferation of complete RNA structure determinations using NMR spectroscopy is in part a result of the availability of rapid and simple methods for isotopic labeling of RNA molecules with either ${ }^{13} \mathrm{C}$ or ${ }^{15} \mathrm{~N}$, which permit heteronuclear experiments to be performed that resolve the severe spectral overlap inherent in the proton spectra of RNAs (Batey et al., 1992, 1995; Nikonowicz et al., 1992). The rapid development of pulse sequences tailored for RNA spin systems has facilitated many structure determinations, and it is now possible, in principle, to obtain complete sequential assignments of RNAs using only through-bond coherence transfer experiments. The process of solving a high-resolution RNA structure by NMR can be subdivided into three major steps as outlined in Figure 7.7.1. In the present discussion, the focus will be on steps II and III, addressing basic issues related to NMR data accumulation and structure calculation.

After sequence-specific assignments of RNAs are obtained, the structure determination is based on collecting sufficient numbers of proton-proton distance restraints utilizing nuclear Overhauser effect correlation spectroscopy (NOESY) experiments. Potentially, these short-distance restraints between pairs of protons $(<6 \AA)$ can be complemented with torsion angle information accessible through J-coupling constants. New experiments to measure orientational rather than distance dependent dipolar couplings, as well as cross-correlated relaxation rates, have been developed providing additional structural information (Reif et al., 1997; Tjandra and Bax, 1997a). In addition, NMR experiments have been introduced that allow the direct identification of donor and acceptor nitrogen atoms involved in hydrogen bonds (Dingley and Grzesick, 1998). These recently introduced parameters are especially important for structure determination of RNA due to the low proton density, and because a significant number of protons are potentially involved in exchange processes. There have been several recent reviews of RNA NMR methodology (Dieckmann and Feigon, 1994; Pardi, 1995; Wijmenga and van Buuren, 1998; Marino et al., 1999), including an exhaustive review by Varani et al. (1996). These reviews give an overview of the structure determination process including resonance assignment, isotopic labeling patterns, NOE identification, coupling constant measurement, and a discussion of recently solved structures. The determination of oligonucleotide structures by NMR is also discussed in UNIT 7.2.

\section{ISOTOPIC LABELING OF RNA}

In order to perform a wide variety of heteronuclear NMR experiments, isotopic enrichment of RNA samples with NMR-active ${ }^{13} \mathrm{C}$ and ${ }^{15} \mathrm{~N}$ nuclei is required. This greatly simplifies the resonance assignments and significantly extends the size limitation for structure determination of RNAs by NMR. Carbon and nitrogen cannot be readily studied with highresolution NMR techniques at natural abundance as the ${ }^{12} \mathrm{C}$ isotope is NMR inactive and the ${ }^{14} \mathrm{~N}$ isotope possesses an electric quadrapole moment. Isotopic labeling techniques of RNAs will not be discussed in great detail, because optimized protocols for the preparation of labeled nucleotides have already been published (Batey et al., 1992, 1995; Nikonowicz et al., 1992); however, the standard method for preparation of isotopically labeled RNA is in vitro transcription from synthetic DNA oligonucleotide templates using T7 RNA polymerase and isotopically labeled nucleotide triphosphates (NTPs). Labeled NTPs can be
Biophysical Analysis of Nucleic Acids 


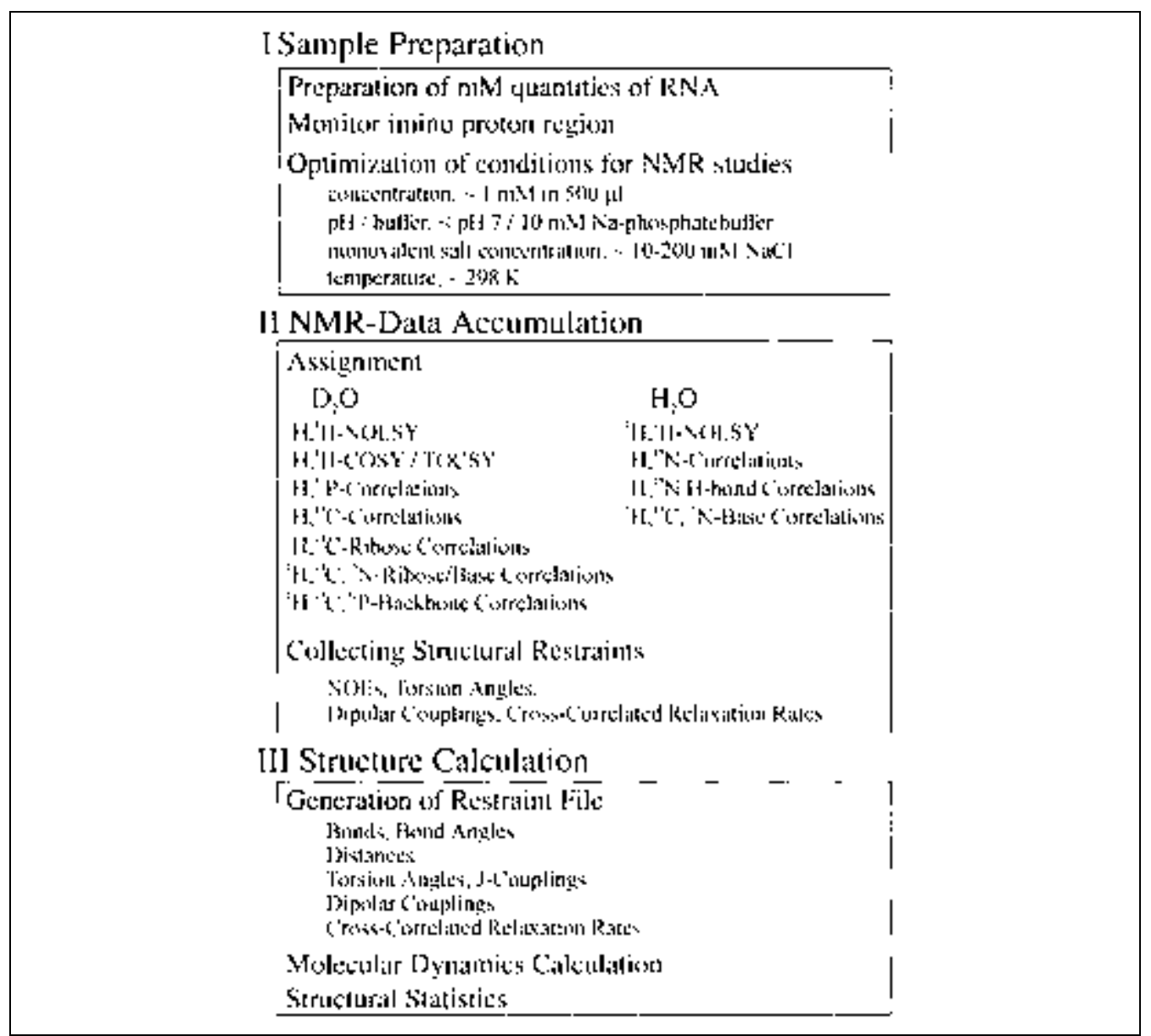

Figure 7.7.1 Schematic protocol for RNA structure determination using heteronuclear NMR spectroscopy. Depending on the observed quality of the various NMR experiments, not all methods for the resonance assignment might be needed. Traditionally used restraint files consist of experimental distances and J-couplings only.

Recent Advances in RNA Structure Determination by NMR

\section{ASSIGNMENT OF RNA NMR RESONANCES}

Before starting the detailed and time-consuming investigation of a chosen RNA by NMR, it is extremely important to optimize the sample conditions for data acquisition from the various required NMR experiments. It is critical to determine at the outset if the system is suitable for a high-resolution NMR structure elucidation.

The imino proton region of the proton NMR spectrum of an unlabeled RNA sample in $\mathrm{H}_{2} \mathrm{O}$ provides a sensitive diagnostic for this purpose. A sample imino proton one-dimensional (1-D) spectrum for a correctly folded 30-mer RNA is shown in Figure 7.7.2. In this spectrum, one peak appears for each Watson-Crick base pair in the molecule. Since the imino protons exchange rapidly with the bulk $\mathrm{H}_{2} \mathrm{O}$, the spectrum was recorded with a jump-return echo sequence that avoids presaturation, while providing the 


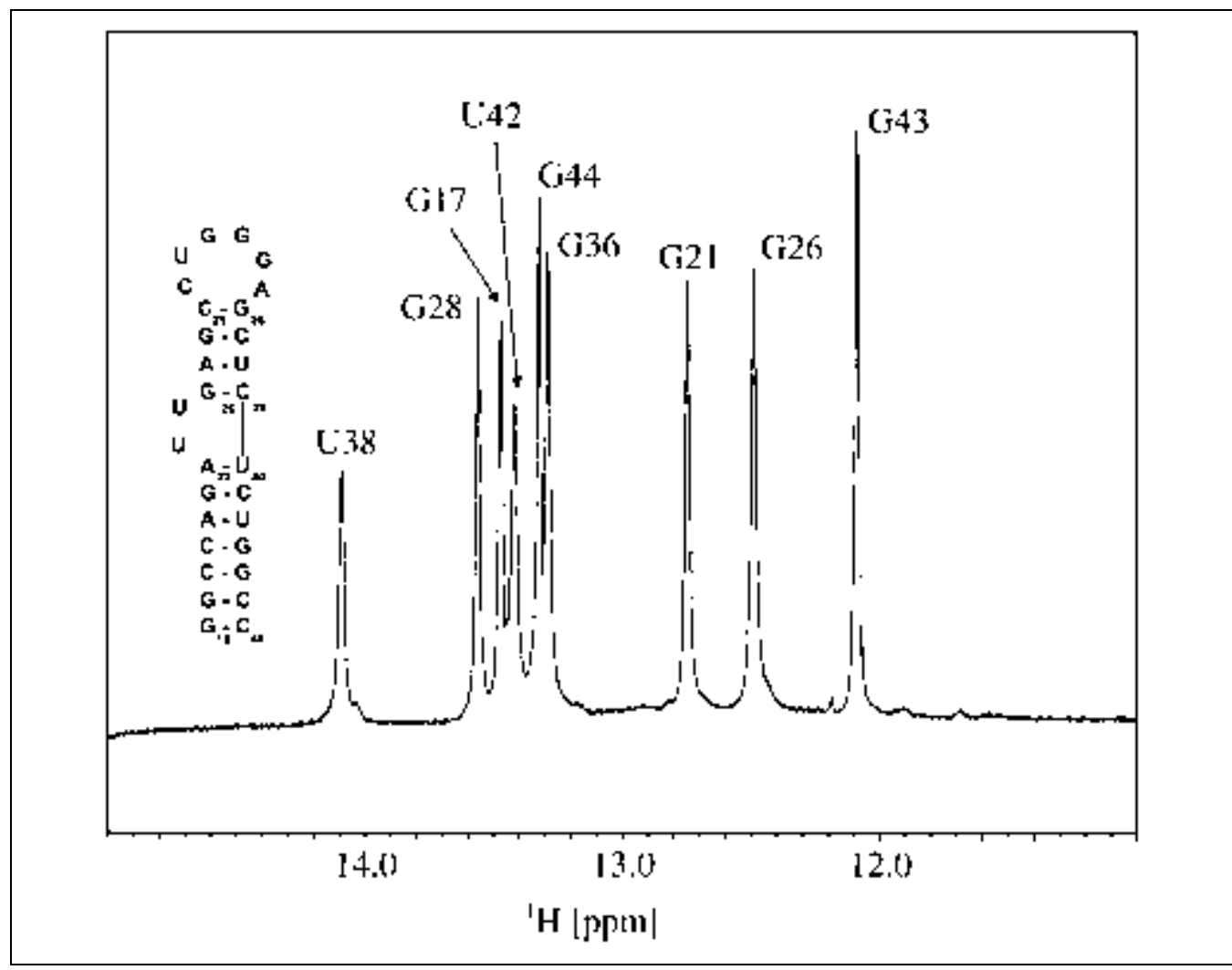

Figure 7.7.2 Imino proton region of HIV-2 TAR RNA (inset) from a jump-return echo 1-D experiment recorded in $90 \% \mathrm{H}_{2} \mathrm{O} / 10 \% \mathrm{D}_{2} \mathrm{O}$ at $298 \mathrm{~K}$. Conditions used are $10 \mathrm{mM}$ sodium phosphate buffer ( $\mathrm{pH} 6.4$ ), $50 \mathrm{mM}$ sodium chloride, and $0.1 \mathrm{mM}$ EDTA. The concentration is $\sim 3.0 \mathrm{mM}$ RNA in $500 \mu \mathrm{L}$.

most efficient water suppression (Sklenar and Bax, 1987). The sample conditions to be surveyed are summarized in Figure 7.7.1. The goal is to obtain the narrowest linewidth and best chemical shift dispersion for the observable imino protons that report on secondary structure formation. A number of factors contribute to the imino proton linewidth, which are typically on the order of 10 to $30 \mathrm{~Hz}$; most important is the rate of exchange with the solvent. The complex kinetics of base-pair opening and imino proton exchange in nucleic acids have been extensively reviewed in the literature and are beyond the scope of this unit (Gueron and Leroy, 1995).

Assignment of RNA resonances has historically been achieved through identification of sequential base to ribose NOE patterns seen in helical regions of nucleic acid structure, in analogy to the procedure originally utilized for DNA studies in the 1980s (Wüthrich, 1986). With the advent of isotopic labeling for RNA, the basic NOE assignment approach was initially expanded to include multidimensional (3-D and 4-D) versions of the standard NOESY, correlation spectroscopy (COSY), and total correlation spectroscopy (TOCSY) 2-D experiments, which simplified assignment and identification of NOEs (Nikonowicz and Pardi, 1992, 1993; Pardi and Nikonowicz, 1992). The NOE-based approach, however, relies on assumptions about structure and assignments and is somewhat susceptible to errors from structural bias. A methodology that achieves sequential assignment via unambiguous through-bond correlation experiments, as is the case for proteins, would be more ideal. The easiest extensions of homonuclear experiments, applicable with labeled samples, are one-bond heteronuclear single quantum coherence (HSQC)- or heteronuclear multiple quantum coherence (HMQC)-type experiments, where the proton resonances are separated in two-dimensional spectra according to the direct bound heteronuclei, e.g. ${ }^{15} \mathrm{~N}$ or ${ }^{13} \mathrm{C}$. These experiments utilize large ${ }^{1} \mathrm{H}-{ }^{15} \mathrm{~N}$ or ${ }^{1} \mathrm{H}-{ }^{13} \mathrm{C}$ one-bond couplings rather than relatively small multiple-bond ${ }^{1} \mathrm{H}$ homonuclear scalar couplings for magnetization transfer. The resulting two-dimensional HSQC or HMQC correlations between ${ }^{1} \mathrm{H}$ and ${ }^{13} \mathrm{C}$ or ${ }^{15} \mathrm{~N}$ spins are integral components of all multidimensional NMR experiments. The dra-
Biophysical Analysis of Nucleic Acids 

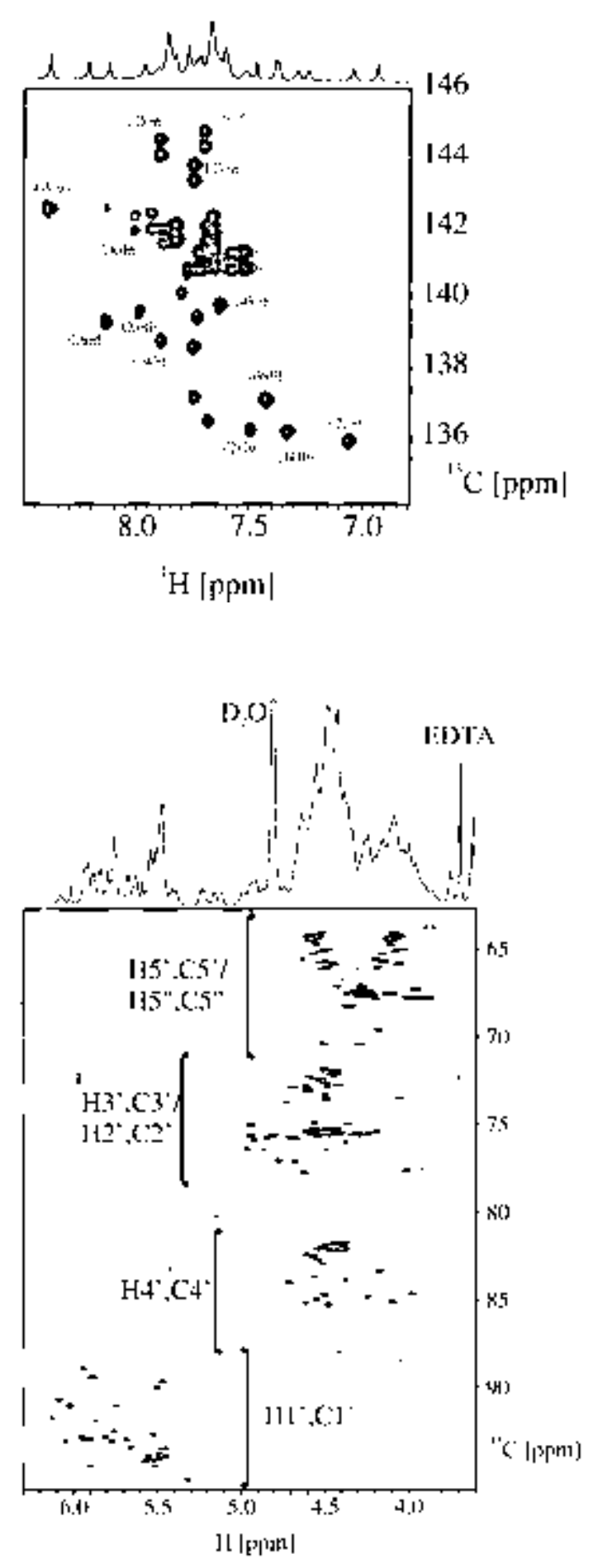

Figure 7.7.3 (Top) The aromatic region of $a{ }^{13} \mathrm{C}-\mathrm{HSQC}$ experiment of HIV-2 TAR RNA. Partial assignments are given in less crowded regions of the spectrum. The corresponding region from a 1-D ${ }^{1} \mathrm{H}$ NMR spectrum recorded in $99.9 \% \mathrm{D}_{2} \mathrm{O}$ at $298 \mathrm{~K}$ is shown on top. ${ }^{1} \mathrm{H},{ }^{13} \mathrm{C}$ correlations arising from $\mathrm{H} 2$ and $\mathrm{C} 2$ resonances of adenosines are not shown. Correlations that arise from $\mathrm{C} 6$ carbon resonances in pyrimidines are split in the carbon dimension due to the homonuclear ${ }^{1} \mathrm{~J}_{\mathrm{CC}}$ coupling constant evolution to the C5 resonance. (Bottom) Ribose region of a ${ }^{13} \mathrm{C}-\mathrm{HSQC}$ experiment of HIV-2 TAR RNA. Nonspecific assignments for the different one-bond correlations are given. The corresponding region from a $1-\mathrm{D}{ }^{1} \mathrm{H}$ NMR spectrum recorded in $99.9 \% \mathrm{D}_{2} \mathrm{O}$ at $298 \mathrm{~K}$ is shown on

Recent Advances in RNA Structure Determination by NMR top. The aromatic $\mathrm{H} 5$ protons of pyrimidines that overlap with the $\mathrm{H} 1^{\prime}$ proton region are not visible in the ${ }^{1} \mathrm{H},{ }^{13} \mathrm{C}$ correlations, because the corresponding $\mathrm{C} 5$ resonates outside the depicted carbon spectral region. Further differences between the 1-D and 2-D experiments arise from incomplete suppression of the HDO and EDTA proton resonances. 
matic gain in resolution for RNA proton resonances bound to carbon is demonstrated in Figure 7.7.3, top panel, for the aromatic ${ }^{1} \mathrm{H},{ }^{13} \mathrm{C}$ region and in Figure 7.7.3, bottom panel, for the ribose ${ }^{1} \mathrm{H},{ }^{13} \mathrm{C}$ spectral region. There has been a proliferation of recent experiments that correlate RNA proton resonances through the heteronuclear spin systems of the base, the ribose ring, and phosphate backbone. Those experiments can be considered as extensions of basic two-dimensional HSQC or HMQC correlations.

The new NMR experiments for resonance assignment can be conceptually organized into four classes (Fig. 7.7.4 and Table 7.7.1). Con- ceptually, the names given to the through-bond correlation experiments are derived from the series of nuclei through which magnetization is transferred during the experiment. The nuclei that undergo chemical shift evolution during the experiment are given in capital letters, sugar and base resonances are specified using subscripted lower case letters, and intervening nuclei, through which magnetization is transferred but which are not directly observed, are enclosed in parentheses. For example, the $\mathrm{H}_{\mathrm{s}}\left(\mathrm{C}_{\mathrm{s}} \mathrm{N}_{\mathrm{b}} \mathrm{C}_{\mathrm{b}}\right) \mathrm{H}_{\mathrm{b}}$ experiment shown in Figure 7.7.4, panel $\mathrm{C}$, correlates the $\mathrm{H}^{\prime}$ ' sugar proton $\left(\mathrm{H}_{\mathrm{s}}\right)$ via transfer of magnetization to the directly attached $\mathrm{C} 1^{\prime}$ sugar carbon $\left(\mathrm{C}_{\mathrm{s}}\right)$. Subsequently, a)

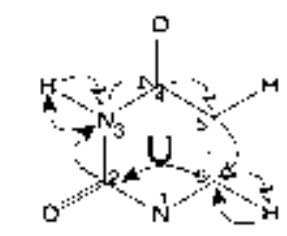

ต

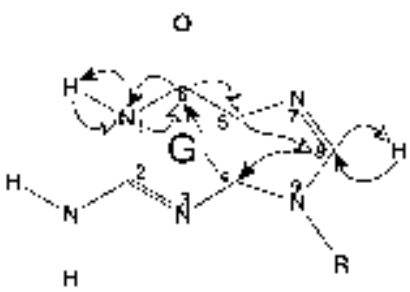

b)

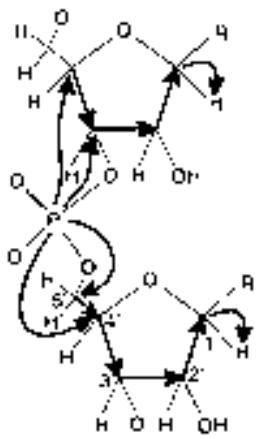

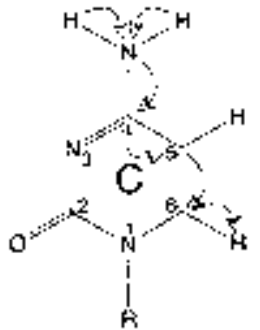

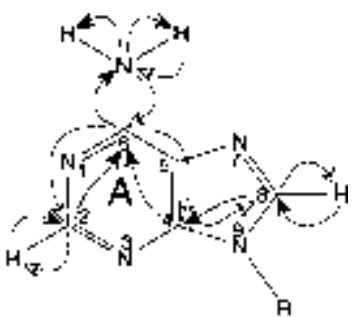

c)

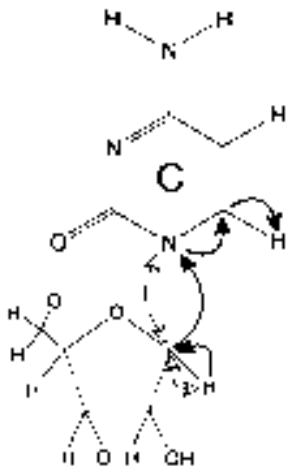

Figure 7.7.4 Schematic of coherence transfer for through-bond assignment experiments. (a) HCN correlation experiments for assignment of the base resonances. Closed and open arrows show HC-TOCSY-CNH and HNC-TOCSY-CH experiments, respectively. (b) HCP experiments for sequential ribose-ribose assignment. (c) $\mathrm{HCN}$ experiments for intranucleotide correlation of base and ribose resonances. Closed arrows show the sequential $\mathrm{H}_{\mathrm{s}}-\mathrm{to}_{\mathrm{b}}-\mathrm{H}_{\mathrm{b}}$ correlation. Open arrows show one of the out-and-back experiments $\left(\mathrm{H}_{\mathrm{s}} \mathrm{C}_{\mathrm{s}} \mathrm{N}_{\mathrm{b}}\right)$. See Table 7.7.1 for a more complete listing of all types of experiments. Numbering conventions are included for each of the base and ribose positions.

Biophysical Analysis of Nucleic Acids 
Table 7.7.1 Through-Bond Correlation Experiments for Assignment of RNA Resonances

\begin{tabular}{|c|c|c|c|}
\hline Experiment & Nucleotide & Coherence pathway $^{a}$ & Reference \\
\hline \multicolumn{4}{|c|}{ Base-base (carried out in $\mathrm{H}_{2} \mathrm{O},{ }^{13} \mathrm{C} /{ }^{15} \mathrm{~N}$-labeled sample) } \\
\hline $\mathrm{H}(\mathrm{NC})-\mathrm{TOCSY}-(\mathrm{C}) \mathrm{H}$ & Guanosine & $\underset{\mathrm{H} 1(\mathrm{t} 1) \rightarrow \mathrm{I} 1 \rightarrow \mathrm{N} 1 \rightarrow \mathrm{C} 6 / \mathrm{C} 2 \rightarrow \mathrm{C} 8 \rightarrow \mathrm{H} 8(\mathrm{t} 2)}{\mathrm{HT}}$ & Simorre et al. (1996a) \\
\hline $\mathrm{H}(\mathrm{C})-\mathrm{TOCSY}-\mathrm{CH}$ & Adenosine & 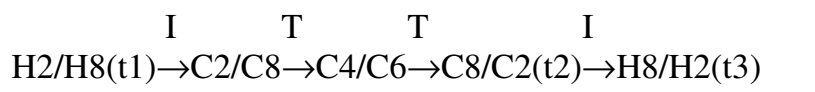 & $\begin{array}{l}\text { Legault et al. (1994); } \\
\text { Marino et al. (1994a) }\end{array}$ \\
\hline (H)N(C)-TOCSY-(C)H & Adenosine & $\underset{\mathrm{H} 6 \rightarrow \mathrm{N} 6(\mathrm{t} 1) \rightarrow \mathrm{C} 6 \rightarrow \mathrm{C} 8 / \mathrm{C} 2 \rightarrow \mathrm{HT} 8 / \mathrm{H} 2(\mathrm{t} 2)}{\mathrm{T}} \underset{\mathrm{I}}{\mathrm{H}}$ & Simorre et al. (1996b) \\
\hline \multirow[t]{2}{*}{$\mathrm{H}(\mathrm{NCCC}) \mathrm{H}$} & Uridine & $\underset{\mathrm{H} 3(\mathrm{t} 1) \rightarrow \mathrm{I} 33 \rightarrow \mathrm{C} 4 \rightarrow \mathrm{C} 5 \rightarrow \mathrm{C} 6 \rightarrow \mathrm{H} 6(\mathrm{t} 2)}{\mathrm{I}}$ & Simorre et al. (1995) \\
\hline & Cytosine & $\underset{\mathrm{H} 4(\mathrm{t} 1) \rightarrow \mathrm{HT} 4 \rightarrow \mathrm{C} 4 \rightarrow \mathrm{C} 5 \rightarrow \mathrm{C} 6 \rightarrow \mathrm{H} 6(\mathrm{t} 2)}{\mathrm{HT}}$ & Simorre et al. (1995) \\
\hline HC-TOCSY-(CN)H ${ }^{b}$ & Purine & $\underset{\mathrm{H} 8 / \mathrm{H} 2(\mathrm{t} 1) \rightarrow \mathrm{C} 8 / \mathrm{C} 2(\mathrm{t} 2) \rightarrow \mathrm{T}}{\mathrm{I}} \underset{\mathrm{C} 6 \rightarrow \mathrm{N} 6 / \mathrm{N} 1 \rightarrow \mathrm{H} 6 / \mathrm{H} 1(\mathrm{t} 3)}{\mathrm{I}}$ & Fiala et al. (1996) \\
\hline \multirow[t]{2}{*}{$\mathrm{H}(\mathrm{C})-\mathrm{TOCSY}-(\mathrm{CN}) \mathrm{H}^{b}$} & Guanosine & $\underset{\mathrm{H} 8(\mathrm{t} 1) \rightarrow \mathrm{C} 8 \rightarrow \mathrm{C} 6 \rightarrow \mathrm{N} 1 \rightarrow \mathrm{H} 1(\mathrm{t} 2)}{\mathrm{HT}}$ & Sklenar et al. (1996) \\
\hline & Uridine & $\underset{\mathrm{H} 6(\mathrm{t} 1) \rightarrow \mathrm{I} 6 \rightarrow \mathrm{HT}}{\mathrm{HT}} \underset{\mathrm{I}}{\rightarrow \mathrm{H} 3(\mathrm{t} 2)}$ & Sklenar et al. (1996) \\
\hline \multicolumn{4}{|c|}{ Base-sugar (preferably carried out in $\mathrm{D}_{2} \mathrm{O},{ }^{13} \mathrm{C} /{ }^{15} \mathrm{~N}$-labeled sample) } \\
\hline $\mathrm{H}_{\mathrm{s}}\left(\mathrm{C}_{\mathrm{s}} \mathrm{N}_{\mathrm{b}} \mathrm{C}_{\mathrm{b}}\right) \mathrm{H}_{\mathrm{b}}^{b}$ & All & $\underset{\mathrm{H} 1^{\prime}(\mathrm{t} 1) \rightarrow \mathrm{Cl}^{\prime} \rightarrow \mathrm{N} 9 / \mathrm{N} 1 \rightarrow \mathrm{C} 8 / \mathrm{C6} 6 \rightarrow \mathrm{H} 8 / \mathrm{H} 6(\mathrm{t} 2)}{\mathrm{I}}$ & Sklenar et al. (1993b) \\
\hline $\mathrm{H}_{\mathrm{s}} \mathrm{C}_{\mathrm{s}} \mathrm{N}_{\mathrm{b}}^{b}$ & All & $\underset{\mathrm{H} 1^{\prime} \rightarrow \mathrm{C} 1^{\prime}(\mathrm{t} 1) \rightarrow \mathrm{I}}{\mathrm{I}} \underset{\mathrm{N} 9 / \mathrm{N} 1(\mathrm{t} 2) \rightarrow \mathrm{C} 1^{\prime} \rightarrow \mathrm{H} 1^{\prime}(\mathrm{t} 3)}{\mathrm{I}}$ & $\begin{array}{l}\text { Heus et al. (1994); } \\
\text { Marino et al. (1994b) }\end{array}$ \\
\hline $\mathrm{H}_{\mathrm{b}} \mathrm{C}_{\mathrm{b}} \mathrm{N}_{\mathrm{b}}^{f}$ & All & 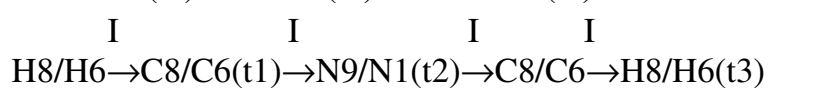 & $\begin{array}{l}\text { Heus et al. (1994); } \\
\text { Marino et al. (1994b) }\end{array}$ \\
\hline $\mathrm{H}_{\mathrm{s}} \mathrm{C}_{\mathrm{s}}\left(\mathrm{N}_{\mathrm{b}} \mathrm{C}_{\mathrm{b}}\right) \mathrm{H}_{\mathrm{b}}$ & All & 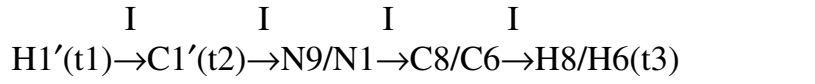 & Farmer et al. (1993) \\
\hline $\mathrm{H}_{\mathrm{s}} \mathrm{C}_{\mathrm{s}} \mathrm{N}_{\mathrm{b}}$ & Purine & $\underset{\mathrm{H} 1^{\prime} \rightarrow \mathrm{C} 1^{\prime}(\mathrm{t} 1) \rightarrow \mathrm{I}}{\mathrm{I}} \underset{\mathrm{N} 9(\mathrm{t} 2) \rightarrow \mathrm{I} \mathrm{C}^{\prime} \rightarrow \mathrm{I} 1^{\prime}(\mathrm{t} 3)}{\mathrm{I}}$ & Farmer et al. (1994) \\
\hline $\mathrm{H}_{\mathrm{s}} \mathrm{C}_{\mathrm{s}}\left(\mathrm{N}_{\mathrm{b}}\right) \mathrm{C}_{\mathrm{b}}$ & Purine & 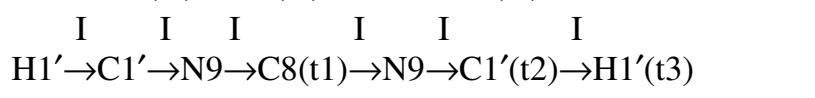 & Farmer et al. (1994) \\
\hline $\mathrm{H}_{\mathrm{b}} \mathrm{N}_{\mathrm{b}} \mathrm{C}_{\mathrm{b}}$ & Purine & $\underset{\mathrm{H} 8 \rightarrow \mathrm{I}}{\mathrm{I} 9(\mathrm{t} 1) \rightarrow \mathrm{I}} \underset{\mathrm{C} 8(\mathrm{t} 2) \rightarrow \mathrm{I}}{\mathrm{I}} \rightarrow \mathrm{H}(\mathrm{t} 3)$ & Farmer et al. (1994) \\
\hline \multicolumn{4}{|c|}{ Phosphate-backbone (preferably carried out in $\mathrm{D}_{2} \mathrm{O},{ }^{13} \mathrm{C}$-labeled sample) } \\
\hline $\mathrm{HCP}$ & All & $\underset{\mathrm{H} 4^{\prime} \rightarrow \mathrm{C} 4^{\prime} \rightarrow \mathrm{I}}{\mathrm{I}} \underset{\mathrm{P}(\mathrm{t} 1) \rightarrow \mathrm{C} 4^{\prime}(\mathrm{i}+1)(\mathrm{t} 2) \rightarrow \mathrm{I} 4^{\prime}(\mathrm{i}+1)^{\prime}(\mathrm{t} 3)}{\mathrm{I})}$ & $\begin{array}{l}\text { Heus et al. (1994); } \\
\text { Marino et al. (1994b) }\end{array}$ \\
\hline HCP-CCH-TOCSY & All & 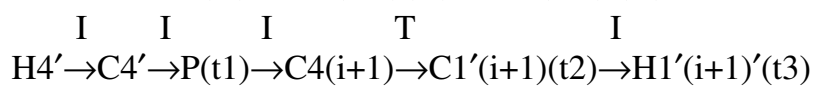 & Marino et al. (1995) \\
\hline P(CC)H-TOCSY & All & $\underset{\mathrm{P}(\mathrm{t} 1) \rightarrow \mathrm{C} 4^{\prime}(\mathrm{i}, \mathrm{i}+1) \rightarrow \mathrm{C} 1^{\prime}(\mathrm{i}, \mathrm{i}+1) \rightarrow \mathrm{HT} 1^{\prime}(\mathrm{i}, \mathrm{i}+1)^{\prime}(\mathrm{t} 2)}{\mathrm{H}}$ & Wijmenga et al. (1995) \\
\hline $\mathrm{P}(\mathrm{H}) \mathrm{H}-\mathrm{TOCSY}$ & All & $\underset{\mathrm{P}(\mathrm{t} 1) \rightarrow \mathrm{HT}}{\mathrm{H} 3^{\prime} / 4^{\prime} / 5^{\prime}(\mathrm{i}, \mathrm{i}+1) \stackrel{\mathrm{T}}{\rightarrow} \rightarrow \mathrm{H} 1^{\prime} / 2^{\prime} / 3^{\prime} / 4^{\prime} / 5^{\prime}(\mathrm{i}, \mathrm{i}+1)^{\prime}(\mathrm{t} 2)}$ & Kellogg (1992) \\
\hline
\end{tabular}

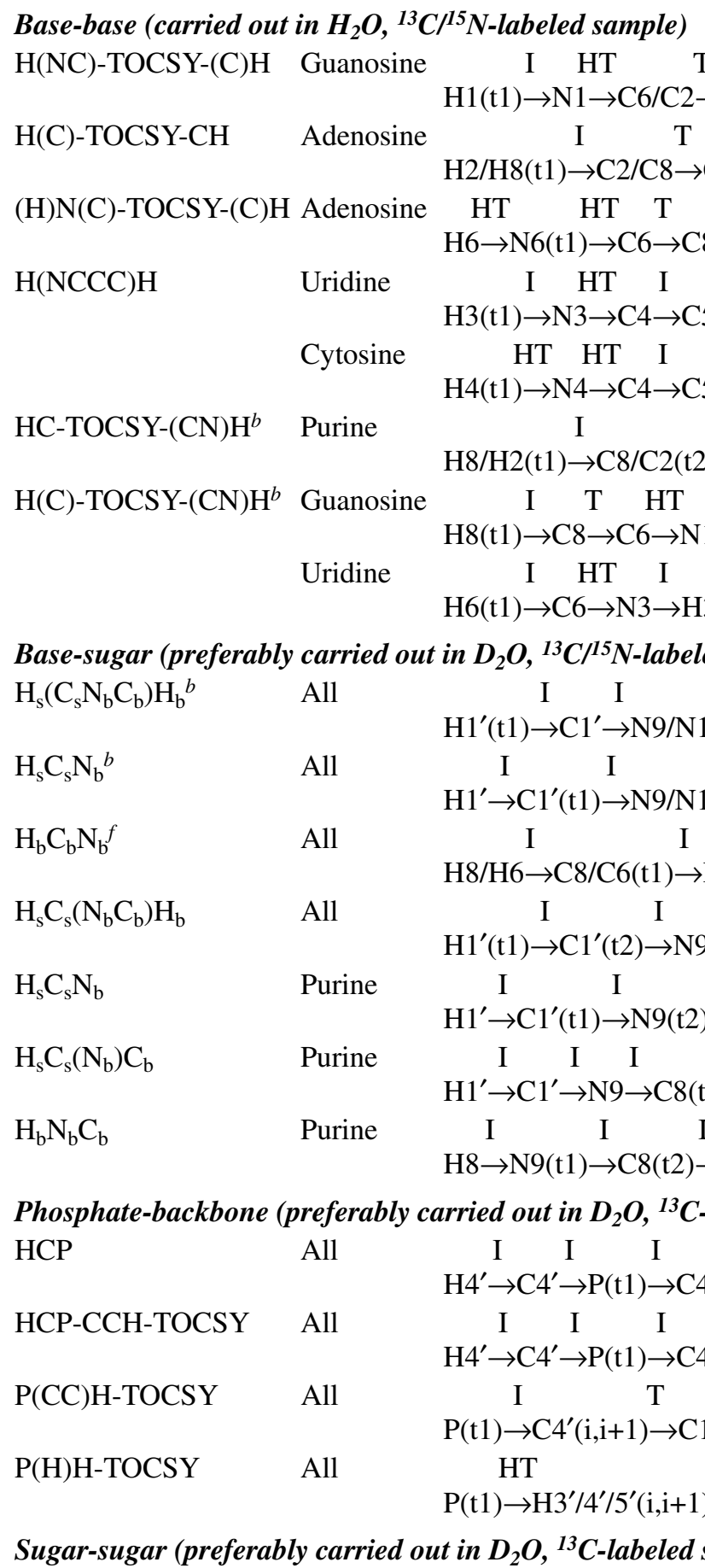

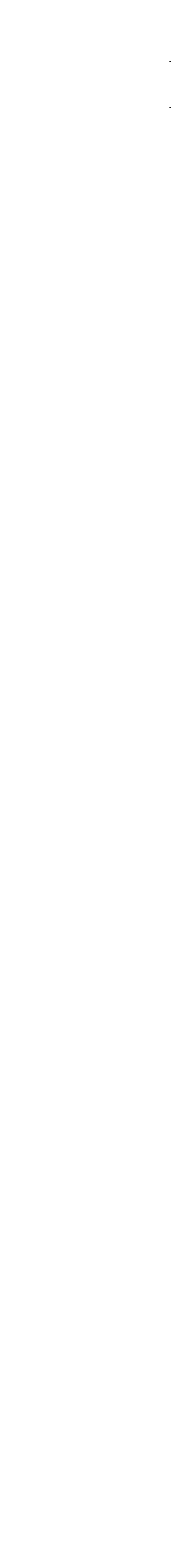

HCCH-COSY All I I I

$\begin{array}{lllll} & \mathrm{H} 1-5^{\prime} \rightarrow \mathrm{C} 1-5^{\prime}(\mathrm{t} 1) \rightarrow \mathrm{C}(\mathrm{i} \pm 1)^{\prime}(\mathrm{t} 2) \rightarrow \mathrm{H}(\mathrm{i} \pm 1)^{\prime}(\mathrm{t} 3) & \text { Fesik et al. (1990) }\end{array}$

$\begin{array}{cccc} & \mathrm{H} 1-5^{\prime} \rightarrow \mathrm{C} 1-5^{\prime}(\mathrm{t} 1) \rightarrow \mathrm{C}(\mathrm{i} \pm \mathrm{n})^{\prime}(\mathrm{t} 2) \rightarrow \mathrm{H}(\mathrm{i} \pm \mathrm{n})^{\prime}(\mathrm{t} 3) & \text { Hu et al. (1998); }\end{array}$

$\mathrm{H} 1-5^{\prime} \rightarrow \mathrm{C} 1-5^{\prime}(\mathrm{t} 1) \rightarrow \mathrm{C}(\mathrm{i}+\mathrm{n})^{\prime}(\mathrm{t} 2) \rightarrow \mathrm{H}(\mathrm{i}+\mathrm{n})^{\prime}(\mathrm{t} 3) \quad$ Schwalbe et al. (1995)

${ }^{a}$ The letter above the arrow indicates the type of coherence transfer method used: I - INEPT, T-TOCSY, HT-Hetero-TOCSY. In parentheses are the ( $\mathrm{t}_{1}$, $\mathrm{t}_{2}, \mathrm{t}_{3}$ ) dimensions for which chemical shift is detected.

${ }^{b}$ Experiment titles have been slightly altered in order to be presented in a uniform fashion. Parentheses indicate a nucleus that coherence is transfered through, but the chemical shift is not detected.

\subsection{6}


magnetization is transferred via ${ }^{1} \mathrm{~J}_{\mathrm{NC}}$ couplings to the $\mathrm{N} 9$ (for purines) or $\mathrm{N} 1$ (for pyrimidines) nitrogens $\left(\mathrm{N}_{\mathrm{b}}\right)$, and further to the directly attached $\mathrm{C} 8$ (for purines) or $\mathrm{C} 6$ (for pyrimidines) base carbons $\left(\mathrm{C}_{\mathrm{b}}\right)$. Finally, magnetization is transferred to the base protons $\left(\mathrm{H}_{\mathrm{b}}, \mathrm{H} 8 / \mathrm{H} 6\right.$ for purines and pyrimidines, respectively) for detection ( $\mathrm{t} 1$ chemical shift evolution period). Thus, the $\mathrm{H}_{\mathrm{s}}\left(\mathrm{C}_{\mathrm{s}} \mathrm{N}_{\mathrm{b}} \mathrm{C}_{\mathrm{b}}\right) \mathrm{H}_{\mathrm{b}}$ experiment is a twodimensional experiment correlating sugar to base protons. The $\mathrm{C}_{\mathrm{s}} \mathrm{N}_{\mathrm{b}} \mathrm{C}_{\mathrm{b}}$ pathway for magnetization transfer is required to connect the $\mathrm{H}_{s}$ and $\mathrm{H}_{\mathrm{b}}$, but is not directly recorded in the experiment.

The HCN class correlates the protons of the bases (both exchangeable and non-exchangeable) to one another via $\mathrm{J}_{\mathrm{CC}}$ and $\mathrm{J}_{\mathrm{CN}}$ couplings (Sklenar et al., 1987; Simorre et al., 1995, 1996a,b; Fiala et al., 1996), while another HCN class correlates the base resonances (H8/H6) to the ribose $\mathrm{H1}^{\prime}$ proton through the intervening carbon $\left(\mathrm{C} 8 / \mathrm{C} 6 / \mathrm{Cl}^{\prime}\right)$ and nitrogen (N9/N1) resonances (Farmer et al., 1993, 1994; Sklenar et al., 1993a,b). An HCP class of experiments correlates the sugar resonances of sequential nucleotides through the phosphate backbone (Heus et al., 1994; Marino et al., 1994b, 1995; Varani et al., 1995; Wijmenga et al., 1995). Finally, the extended versions of homonuclear COSY and TOCSY experiments utilizing large one-bond ${ }^{1} \mathrm{~J}_{\mathrm{HC}}$ and ${ }^{1} \mathrm{~J}_{\mathrm{CC}}$ coupling constants for the coherence transfer between ribose proton and carbon resonances comprise the $\mathrm{HCCH}$ class. Heteronuclear chemical shifts relevant for the experiments discussed below are summarized in Table 7.7.2.

\section{Base HCN Correlation Experiments}

A set of HNCCH- and HCCNH-TOCSY experiments have been developed that correlate the exchangeable imino and amino proton resonances with the nonexchangeable base resonances for the complicated spin systems of all four nucleotides (Sklenar et al., 1987; Simorre et al., 1995, 1996a,b; Fiala et al., 1996; Wöhnert et al., 1999). In contrast to the poor chemical shift dispersion of the different ribose protons, the imino proton resonances show reasonably good dispersion mainly due to varying hydrogen-bonding networks and stacking effects of base pairing in RNAs as shown in Figure 7.7.5. Unfortunately, amino groups frequently undergo rotation around the carbon-nitrogen bonds, which can result in intermediate exchange for the attached $\mathrm{NH}_{2}$ proton resonances, resulting in a broad linewidth, as can be seen in Figure 7.7.6.

Table 7.7.2 Heteronuclear Chemical Shifts in Nucleotides

\begin{tabular}{ll}
\hline Atom(s) & Chemical shift range \\
\hline Carbon & \\
Purine C5 & $\sim 120 \mathrm{ppm}$ \\
Purine C8 & $\sim 140 \mathrm{ppm}$ \\
Purine C2,C4,C6 & $\sim 150-160 \mathrm{ppm}$ \\
Pyrimidine C5 & $\sim 100 \mathrm{ppm}$ \\
Pyrimidine C6 & $\sim 145 \mathrm{ppm}$ \\
Pyrimidine C2,C4 & $\sim 155-170 \mathrm{ppm}$ \\
Ribose carbons & $\sim 70-90 \mathrm{ppm}$ \\
Nitrogen & \\
Purine N9 & $\sim 170 \mathrm{ppm}$ \\
Purine N7 & $\sim 220-240 \mathrm{ppm}$ \\
Guanosine N1 & $\sim 145-150 \mathrm{ppm}$ \\
Guanosine N2 & $\sim 70-80 \mathrm{ppm}$ \\
Guanosine N3 & $\sim 160-165 \mathrm{ppm}$ \\
Adenosine N1 & $\sim 220 \mathrm{ppm}$ \\
Adenosine N3 & $\sim 215 \mathrm{ppm}$ \\
Adenosine N6 & $\sim 80-90 \mathrm{ppm}$ \\
Pyrimidine N1 & $\sim 145-150 \mathrm{ppm}$ \\
Uridine N3 & $\sim 150-160 \mathrm{ppm}$ \\
Cytosine N3 & $\sim 195-200 \mathrm{ppm}$ \\
Cytosine N4 & $\sim 95 \mathrm{ppm}$ \\
\hline &
\end{tabular}

Biophysical Analysis of Nucleic Acids 


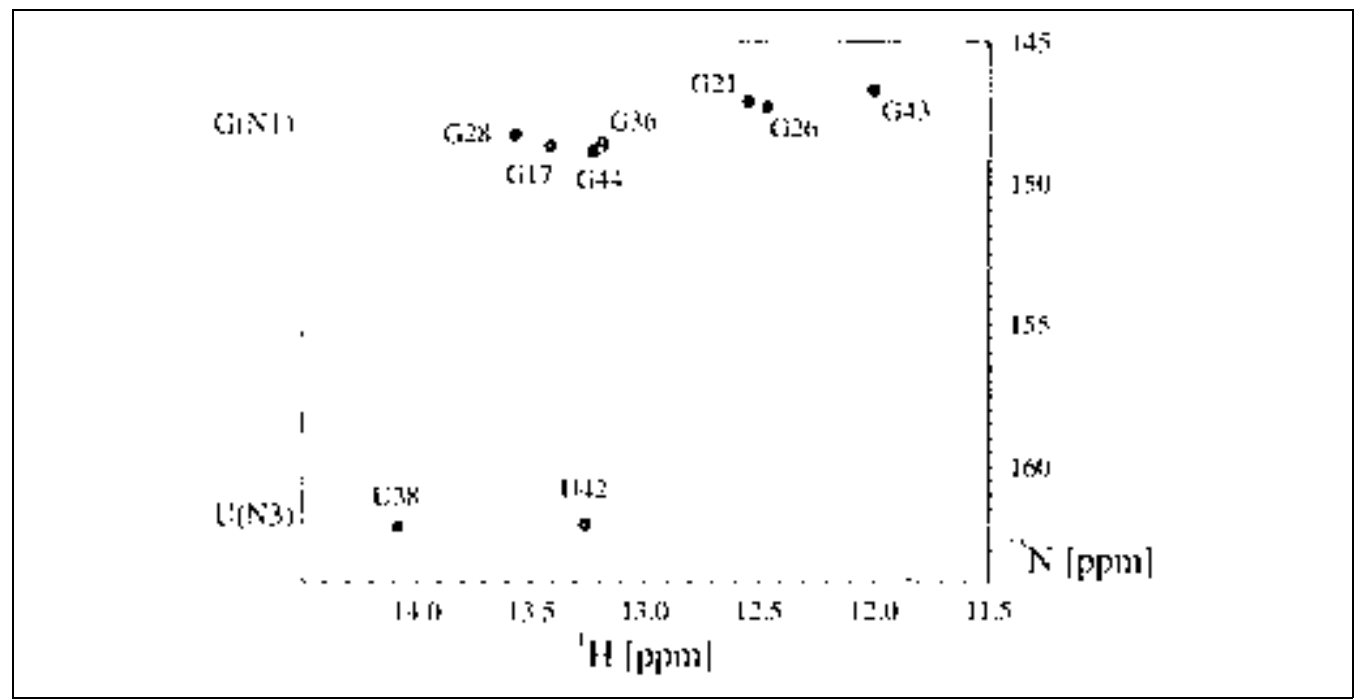

Figure 7.7.5 Assignments of the imino region of the HIV-2 TAR argininamide complex from a jump-return HMQC experiment recorded in $90 \% \mathrm{H}_{2} \mathrm{O} / 10 \% \mathrm{D}_{2} \mathrm{O}$ at $298 \mathrm{~K}$. The terminal 5'G.C3' $\mathrm{G} 16$ imino resonance as well as the $\mathrm{U} 40$ imino resonance from the base-pair that terminates the upper stem are missing due to unfavorable exchange properties with the solvent.

The HCN correlation experiments differ in the exact mechanism of magnetization transfer, but predominantly rely on one-bond heteronuclear coupling constants to transfer magnetization from protons to the heteronuclei of the ring, and homonuclear ${ }^{13} \mathrm{C}$-TOCSYs to transfer magnetization across the ring. There are two important issues which impinge upon the sensitivity of these experiments. One is the chemi- cal shift differences between the carbon resonances in the ring. The efficiency of homonuclear ${ }^{13} \mathrm{C}$-TOCSY transfers relies on the elimination of chemical shift differences as achieved by the spin-lock mixing schemes. The large bandwidth of carbon resonances associated with the different bases require radio frequency (rf) powers beyond current instrumental limitations for efficient carbon spin lock. Therefore,

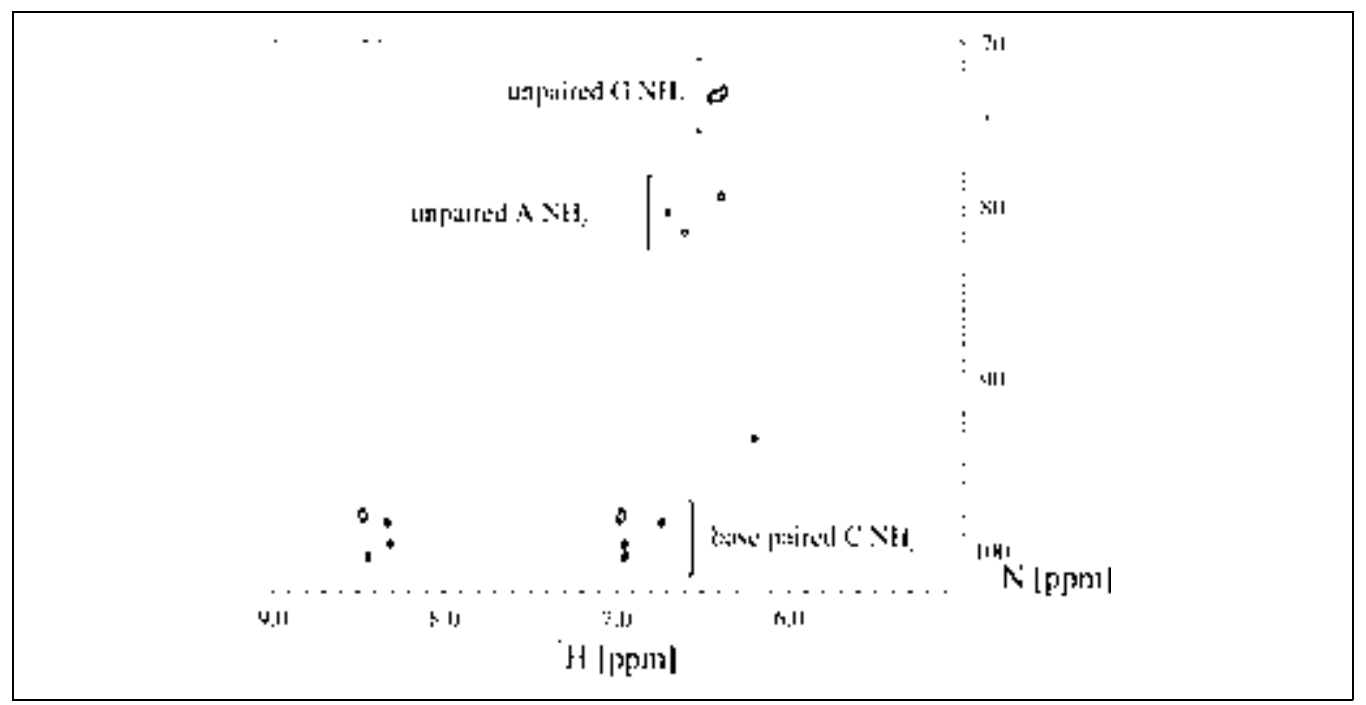

Figure 7.7.6 Residue-type specific assignments of the amino region of the $\phi_{21}$ boxB RNA hairpin complexed to a 19-amino acid bacteriophage $\mathrm{N}^{\lambda}$ peptide (Cilley and Williamson, 1997) from an HSQC experiment recorded in $90 \% \mathrm{H}_{2} \mathrm{O} / 10 \% \mathrm{D}_{2} \mathrm{O}$ at $298 \mathrm{~K}$. In the case of cytidine amino residues involved in base-pairing interaction, the rotation around the $\mathrm{C}-\mathrm{N}$ bond is sufficiently slow to observe

Recent Advances in RNA Structure Determination by NMR two distinct proton resonance frequencies; however, the amino resonances of base-paired guanosines and adenosines are generally not observable due to intermediate exchange at $298 \mathrm{~K}$. The only observable resonances are those of unpaired purine residues. Only one proton resonance is observable, indicative of fast exchange on the NMR time scale. 
magnetization is usually transferred via smaller two-bond carbon-carbon $\left({ }^{2} \mathrm{~J}_{\mathrm{CC}}\right)$ coupling constants (C8-C4-C6 for purines and C6-C4 for pyrimidines), which require long spin-lock mixing times for transfer and loss of sensitivity due to fast carbon transverse relaxation. Alternatively, sequential homonuclear insensitive nuclei enhanced by polarization (INEPT) transfers (C4-C5-C6) can be used rather than a ${ }^{13} \mathrm{C}$-TOCSY H(NCCC)H for pyrimidines ( $\mathrm{Si}-$ morre et al., 1995). For purines, a broad-band spin-locking scheme (Mohebbi and Shaka, 1991) can be used to increase the efficiency of one-bond carbon-carbon transfer and decrease mixing times (Simorre et al., 1996a,b). Adenines have a network of homonuclear ${ }^{2} \mathbf{J}_{\mathrm{CC}}$ and ${ }^{3} \mathrm{~J}_{\mathrm{CC}}$ couplings, allowing the assignments of nonexchangeable $\mathrm{H} 2$ and $\mathrm{H} 8$ base proton resonances using HCCH-TOCSY experiments (Legault et al., 1994; Marino et al., 1994a). Magnetization between the $\mathrm{H} 2$ and $\mathrm{H} 8$ protons can be transferred through the intervening carbon using a broad-band spin-locking scheme (Mohebbi and Shaka, 1991).

Another factor, which decreases the sensitivity, is rotational exchange broadening of exocyclic amino protons on adenine, guanine, or cytosine. More efficient ${ }^{1} \mathrm{H},{ }^{15} \mathrm{~N}$-transfer techniques than the standard INEPT procedure have to be used when proton resonances are broadened by rotational exchange (Mueller et al., 1995). In addition, the nitrogen linewidths are narrower than the corresponding protons undergoing chemical exchange as shown in Figure 7.7.6, and detection of nitrogen chemical shift rather than proton is more efficient (Simorre et al., 1995, 1996b). The extra sensitivity gained by optimization is offset by increased experiment time for acquiring a separate data set for each nucleotide. Nevertheless, the added sensitivity probably will be essential for assigning the resonances of many larger RNAs.

\section{Base-to-Ribose Correlation Experiments}

An important application of ${ }^{13} \mathrm{C} /{ }^{15} \mathrm{~N}$-labeling of RNA is through-bond intranucleotide correlation of base-to-ribose resonances, which historically has been achieved through NOE transfer. There are now many published experiments for achieving this through bond transfer (Farmer et al., 1993, 1994; Sklenar et al., 1993a,b), which are reviewed by Dieckmann and Feigon (1994) and Pardi (1995). A simple sequential INEPT transfer procedure with nonselective pulses can be used to provide sugarto-base correlations. Branching coherence transfer pathways occurring due to ${ }^{1} \mathrm{~J}_{\mathrm{NC}}$ couplings of similar size and thus correlating $\mathrm{N} 9 / \mathrm{N} 1$ to $\mathrm{C} 8 / \mathrm{C} 6$ as well as $\mathrm{C} 4 / \mathrm{C} 2$ resonances in purines and pyrimidines, however, reduce the sensitivity of the basic approach. In addition, small one-bond ${ }^{1} \mathrm{~J}_{\mathrm{NC}}$ couplings result in relatively inefficient magnetization transfer. Therefore, selective carbon pulses have been cleverly utilized to direct coherence predominantly along the desired pathways. Separate optimized sequences are often required because of sensitivity and overlap problems (Farmer et al., 1994). Acquiring several experiments detecting different heteronuclei (C8/C6, $\mathrm{N} 9 / \mathrm{N} 1$, or $\mathrm{C1}^{\prime}$ ) may resolve overlap problems for larger RNA molecules. The experiments which will provide the best resolution may vary for different RNA molecules and can be best determined empirically from 2-D ${ }^{1} \mathrm{H}-{ }^{13} \mathrm{C}$ or ${ }^{1} \mathrm{H}-{ }^{15} \mathrm{~N}$ HSQCs of the base and $\mathrm{C}^{\prime} / \mathrm{H}^{\prime}{ }^{\prime}$ resonances.

\section{Phosphate Backbone HP and HCP Correlation Experiments}

In order to link the resonances of each ribonucleotide sequentially without the use of NOEs, magnetization must be transferred through the phosphate backbone. For unlabeled RNAs, a number of relatively efficient ${ }^{1} \mathrm{H},{ }^{31} \mathrm{P}$ multidimensional correlation schemes are available for sequential assignment of ${ }^{31} \mathrm{P}$ and ribose ${ }^{1} \mathrm{H}$ resonances. Magnetization can be transferred from excited ${ }^{31} \mathrm{P}$ resonances to the ${ }^{3} \mathrm{~J}_{\mathrm{HP}}$ scalar coupled ribose protons for detection using either COSY (Sklenar et al., 1986) or heteronuclear TOCSY (Kellogg, 1992) transfer steps. The resulting two-dimensional $\mathrm{H} 3^{\prime} / \mathrm{H}^{\prime} / \mathrm{H} 5^{\prime \prime},{ }^{31} \mathrm{P}$-correlations can be concatenated with homonuclear ${ }^{1} \mathrm{H},{ }^{1} \mathrm{H}$ NOESY or TOCSY experiments to transfer magnetization to potentially better-resolved resonances like $\mathrm{H} 1^{\prime}$ or aromatic H8/H6 resonances (Kellogg and Schweitzer, 1993). A straightforward approach for ${ }^{13} \mathrm{C}$-labeled RNAs is HCP correlation via sequential INEPT transfers (i. e., ${ }^{1} \mathrm{H} \rightarrow$ ${ }^{13} \mathrm{C} \rightarrow{ }^{31} \mathrm{P} \rightarrow{ }^{13} \mathrm{C} \rightarrow{ }^{1} \mathrm{H}$; Heus et al., 1994; Marino et al., 1994b) correlating nuclei of adjacent nucleotides $i$ and $i+1$. This approach has two limitations for complete assignment of RNA molecules over $\sim 20$ nucleotides. One is severe overlap due to poor spectral dispersion of $\mathrm{C}^{\prime}{ }_{i, i+1}$ and $\mathrm{P}_{\mathrm{i}}$ resonances, particularly in A-form helical regions. Second, the better-resolved $\mathrm{C}{ }^{\prime}{ }_{\mathrm{i}}-\mathrm{P}_{\mathrm{i}}-\mathrm{C} 5^{\prime}{ }_{\mathrm{i}+1}$ connectivity requires a separate HCCH-TOCSY experiment to connect the $\mathrm{C}^{\prime}$ and $\mathrm{C}^{\prime}$ resonances on the same nucleotide. Subsequent experiments, HCP-
Biophysical Analysis of Nucleic Acids

Supplement 2 
CCH-TOCSY (Marino et al., 1995) and $\mathrm{P}(\mathrm{CC}) \mathrm{H}-\mathrm{TOCSY}$ (Wijmenga et al., 1995), resolve both problems by combining the $\mathrm{HCP}$ and HCCH-TOCSY experiments and thus resolving relevant correlations on the well-dispersed $\mathrm{C}^{\prime} / \mathrm{H}^{\prime}$ resonances. However, it is not clear whether these experiments will be generally useful for RNA molecules larger than $\sim 30$ nucleotides $(\sim 10 \mathrm{kDa})$, particularly with the severe line broadening of ${ }^{31} \mathrm{P}$ resonances at higher molecular weights and higher magnetic fields.

\section{Ribose-to-Ribose HCCH Correlation Experiments}

The information obtained from homonuclear ${ }^{1} \mathrm{H},{ }^{1} \mathrm{H}-\mathrm{COSY}$ and -TOCSY experiments can be obtained more readily using $\mathrm{HCCH}$ COSY and -TOCSY experiments on ribose rings uniformly labeled with ${ }^{13} \mathrm{C}$, which allows magnetization transfer and chemical shift evolution on the $\mathrm{C} 1^{\prime}$ to $\mathrm{C}^{\prime}$ carbons (Fesik et al., 1990; Kay et al., 1990; Pardi and Nikonowicz, 1992; Nikonowicz and Pardi, 1993; Pardi, 1995). The assignment of the severely overlapped ribose proton resonances is facilitated through the additional carbon dimension, which provides better shift dispersion. Furthermore, the magnetization transfer through the ribose proton spin systems was hampered due to the small ${ }^{3} \mathrm{~J}_{\mathrm{HH}^{-}}$-vicinal coupling, present in most commonly populated A-form RNA, correlating the $\mathrm{H}^{\prime}$ and $\mathrm{H}_{2}^{\prime}$ resonances. $\mathrm{HCCH}-$ type experiments overcome this problem by making use of large and uniform one-bond ${ }^{1} \mathrm{~J}_{\mathrm{HC}}$ and ${ }^{1} \mathrm{~J}_{\mathrm{CC}}$ coupling constants for more efficient coherence transfer. In contrast to vicinal ${ }^{3} \mathbf{J}$ couplings, one-bond couplings are, in general, much less biased due to different conformations present in various structural motifs, thus facilitating resonance assignments based on through-bond correlation experiments. The $\mathrm{HCCH}$-type experiments transfer magnetization from the excited sugar protons to the directly attached carbons. Neighboring carbon resonances can be correlated through scalar ${ }^{1} \mathrm{~J}_{\mathrm{CC}}$ coupling constants utilizing either COSY, relayed-COSY, or TOCSY (Fesik et al., 1990) mixing schemes. Forward-direct TOCSY provides the best sensitivity for magnetization transfer through the whole ribose $\mathrm{J}_{\mathrm{CC}}$ coupling network (Schwalbe et al., 1995; Hu et al., 1998). Finally, all schemes transfer magnetization back to the protons for detection.

Unlike triple-resonance experiments used for proteins, some of the triple-resonance experiments for RNA are not mandatory prereq- uisites for assignments and structure determination. The HCN experiments for correlation of the base resonances are the most likely to succeed with medium-sized RNA molecules (30 to 40 nucleotides, $\sim 10$ to $15 \mathrm{kDa}$ ) due to less spectral overlap and the relatively long relaxation times of the base resonances. Complete through-bond assignment will probably not be feasible for many medium-sized RNAs, since the HCP experiments are most susceptible to relaxation problems. A hybrid approach with HCN and NOESY experiments will likely be the optimal compromise. The HCN experiments can unambiguously determine the intranucleotide correlations within and between the base and ribose resonances, which will significantly reduce the ambiguity present in the complete NOESY-based assignment procedure.

Even assuming no problems due to relaxation, it does not appear that there will be a simple and quick procedure for assignment of RNA molecules. Neglecting the problems with sensitivity or overlap, complete assignment with only through-bond methods still requires a large number of experiments, if all of the optimized sequences are performed ( $\sim$ experiments for the bases, $\sim 3$ experiments to correlate the base resonances to the ribose, and $\sim 2$ to 3 experiments to correlate the ribose resonances). This results in a very rough estimate of $\sim 20$ days measurement time (assuming an average of two days measurement time per experiment) for an RNA sample, with sample concentrations in the $\mathrm{mM}$ range and a molecular weight between 10 and $25 \mathrm{kDa}$, carried out on spectrometers with at least $500 \mathrm{MHz}$ proton resonance frequency. Nevertheless, this is around the same number of experiments and days of measurement time that have been required for many RNA structures solved by the NOE-based method, since multiple samples with different specific labeling patterns (see below) were required to resolve ambiguities in the sequential NOEs (Battiste et al., 1995; Cai and Tinoco, 1996; Dieckmann et al., 1996; Mao and Williamson, 1999; Mao et al., 1999). Despite roughly the same number of experiments, analysis of the spectra for the through-bond experiments should hopefully be quicker and should lower the potential for misassignment inherent in the NOE method.

\section{NOE MEASUREMENT}

The end goal of NMR analysis is usually a structure determination. Despite the method used for assignment of resonances, the main 
source of structural data is still obtained from NOEs, which provide distance restraints for pairs of hydrogen atoms in the RNA molecule. Only short proton-proton distances in the range $<6 \AA$ are accessible through NOESY experiments. The intensity of NOESY cross peaks is approximately proportional to the inverse of the averaged distance to the power of six, $\left\langle 1 / \mathrm{r}_{\mathrm{ij}}{ }^{6}\right\rangle$, assuming an isolated pair of proton spins $i$ and j. This assumption, however, is usually not valid, which complicates the quantitative treatment of NOESY cross-peak intensities. Potential problems with interpretation of obtained NOESY cross-peak intensities in terms of ${ }^{1} \mathrm{H}$ ${ }^{1} \mathrm{H}$ distances in structure calculations arise mainly from a phenomenon called spin diffusion. Spin diffusion causes a breakdown of the isolated spin pair approximation, because other nearby protons provide competing indirect pathways for observing the direct NOE between the two protons. Spin diffusion effects play a role especially when longer NOESY mixing times $(>100 \mathrm{msec})$ are used. This usually leads to damped NOESY cross-peak intensities that build up through the direct pathway, resulting in underestimated interproton distances. Additionally, multistep transfer pathways can occur, resulting in false NOE assignments. For example, the imino protons of guanines might show spin diffusion-mediated NOEs to the nonexchangeable aromatic $\mathrm{H} 5$ and H6 protons of cytidines in Watson-Crick base pairs through the cytidine amino protons. However, in an early stage of the assignment procedure based on NOESY correlations, spin diffu- sion pathways can aid the identification of spin systems. Thus, for assignments, it is recommended to analyze NOESY spectra acquired with shorter $(\sim 50 \mathrm{msec})$ and longer $(\sim 150$ msec) mixing times. The classification of NOE cross peaks for the structure calculation is discussed in more detail below. Sequential assignment of RNA proton resonances can be achieved for lower-molecular-weight systems $(<10 \mathrm{kDa})$ by identification of NOE patterns seen in A-form helical regions. Homonuclear ${ }^{1} \mathrm{H}-{ }^{1} \mathrm{H}$ NOESY in $\mathrm{H}_{2} \mathrm{O}$ and $\mathrm{D}_{2} \mathrm{O}$ solution both potentially contain valuable through-space correlations for the sequential assignment of adjacent nucleotides. Sequential walks using nonexchangeable ribose and aromatic protons can be achieved in canonical A-form helix through the combined analysis of intraresidual $\mathrm{H1}^{\prime}$-toH6/H8 (3.5 and $3.7 \AA$, respectively) and interresidual H1'-to-H6/H8 NOEs ( $4.3 \AA$ ). The relevant distances are illustrated in Figure 7.7.7. Additionally, the short interresidual distances between the $\mathrm{H} 2$ ' ribose and aromatic $\mathrm{H} 6 / \mathrm{H} 8$ proton resonances $(1.7 \AA)$ as shown in Figure 7.7.7 give rise to strong NOE cross-peaks. NOESY data recorded in $\mathrm{H}_{2} \mathrm{O}$ potentially reveal sequential connectivities between imino protons of residues i and i $+1(5.2 \AA)$. Additionally, interresidual imino proton to $\mathrm{H} 6 / \mathrm{H} 8$ aromatic proton NOE cross-peaks (4.3 and 4.4 $\AA$, respectively) might be observable. However, the NOE-based approach is limited and susceptible to errors from structural bias. Most of the expected A-form sequential through-space

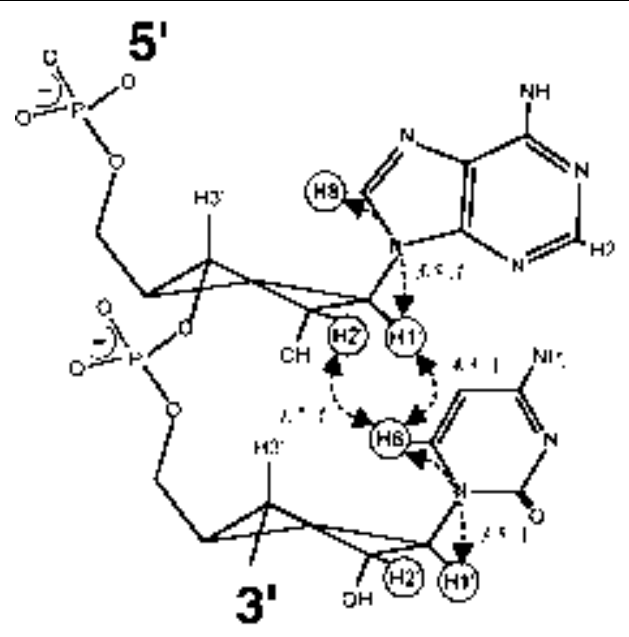

Figure 7.7.7 Classical sequential assignment pathway for A-form helical RNA using intra- and interresidual correlations between $\mathrm{H}^{\prime} / \mathrm{H}^{\prime}$ (i) and $\mathrm{H} 6 / \mathrm{H} 8(\mathrm{i}, \mathrm{i}+1)$ nonexchangeable proton resonances from NOESY experiments. NOESY cross-peaks due to interresidual H2' (i) to H6/H8 (i+1) correlations are usually strong $\left(\mathrm{d}_{\mathrm{HH}} \sim 1.7 \AA\right)$, while intra- and interresidual correlations connecting $\mathrm{H}^{\prime}$ (i) and $\mathrm{H} 6 / \mathrm{H} 8(\mathrm{i}, \mathrm{i}+1)$ protons give rise to weaker cross-peaks $\left(\mathrm{d}_{\mathrm{HH}}=3.5 \AA\right.$ or $\left.4.3 \AA\right)$.

Biophysical Analysis of Nucleic Acids 
connectivities are either missing or altered in noncanonical loop or bulge regions.

Identification of NOEs can be aided by resolving the ${ }^{1} \mathrm{H}-{ }^{1} \mathrm{H}$ NOE connectivities that are essential for determining the structure into three and four dimensions through detection of the heteronuclear $\left({ }^{13} \mathrm{C} /{ }^{15} \mathrm{~N}\right)$ chemical shifts of the proton-attached nuclei (Nikonowicz and Pardi, 1992, 1993). Even with the extra dimensions in 3-D NOESY-HSQC or 4-D HMQCNOESY-HSQC experiments, overlap can still be severe for medium-sized RNAs ( 30 to 40 nucleotides). An approach to aid in the identification of NOEs that has been very successful is selective isotopic labeling of RNA with either heteronuclei $\left({ }^{13} \mathrm{C} /{ }^{15} \mathrm{~N}\right)$ or deuterium $\left({ }^{2} \mathrm{H}\right)$. ${ }^{13} \mathrm{C} /{ }^{15} \mathrm{~N}$-labeled nucleotides can be separated and used individually in in vitro transcriptions with other unlabeled nucleotides (e.g., $\left[{ }^{13} \mathrm{C}\right] \mathrm{GTP}$ plus unlabeled ATP, CTP, and UTP) to produce RNA molecules selectively labeled at only one nucleotide (Nikonowicz et al., 1992; Batey et al., 1995). There are two advantages to selective labeling for identification of NOEs. First, reduced overlap in 3-D NOESY experi- ments, which permits unambiguous identification of more NOEs. Second, isotopic filtering experiments (Otting and Wüthrich, 1989a, 1990) can be performed to help resolve intranucleotide from internucleotide NOEs (Battiste et al., 1995). The introduction of residue-specific ${ }^{13} \mathrm{C}$-labeling in conjunction with isotopic filtering makes it possible to distinguish between different classes of NOEs, namely ${ }^{13} \mathrm{C}-{ }^{1} \mathrm{H}$ to ${ }^{13} \mathrm{C}-{ }^{1} \mathrm{H},{ }^{12} \mathrm{C}-{ }^{1} \mathrm{H}$ to ${ }^{12} \mathrm{C}-{ }^{1} \mathrm{H}$, and ${ }^{12} \mathrm{C}-{ }^{1} \mathrm{H}$ to ${ }^{13} \mathrm{C}$ ${ }^{1} \mathrm{H}$, respectively. This is a particularly powerful approach that can also be utilized for sequential assignment of RNA where the through-bond methods described above are not successful. A similar approach has also been used with RNAs containing site-specific labels produced synthetically at the $\mathrm{C} 8 / \mathrm{C} 6$ positions of the base (SantaLucia et al., 1995; Cai and Tinoco, 1996). One additional labeling methodology that has been developed is specific labeling of a short segment of nucleotides within a larger RNA sequence (Xu et al., 1996). Depending on the RNA being studied and the structural questions being addressed, each of these specific heteronuclear labeling methods will greatly assist in
Recent Advances in RNA Structure Determination by NMR

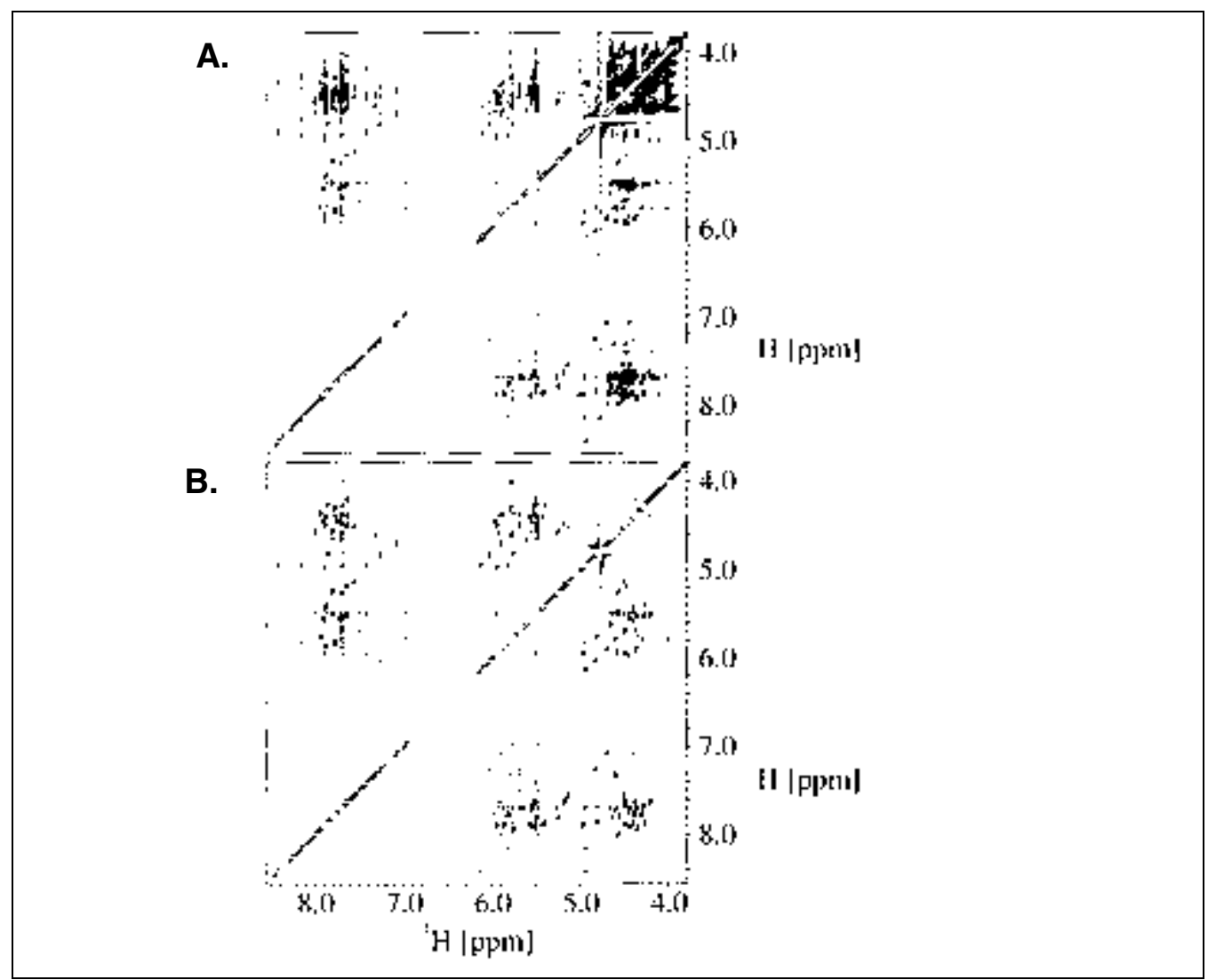

Figure 7.7.8 Effect of specific deuterium labeling on RNA NOESY spectra.(A) NOESY spectrum of unlabeled TAR RNA (30 nucleotides) in $\mathrm{D}_{2} \mathrm{O}$. (B) Same region for d4-TAR RNA which has deuterium labels at the $3^{\prime}, 4^{\prime}, 5^{\prime}$, and $5^{\prime \prime}$ positions of the ribose ring. A dramatic reduction in spectral overlap is evident, and an unusual $2^{\prime}-2^{\prime}$ NOE is observed that could not be identified in heteronuclear NOESY experiments of ${ }^{13} \mathrm{C}$-labeled TAR RNA. 
the assignment and structure determination of medium-sized RNA molecules. In general for medium to large RNAs, several labeled samples are required to obtain unambiguous assignments.

Another way to remove or filter proton resonances is to specifically substitute them with deuterium. An advantage of deuteration, not present with specific ${ }^{13} \mathrm{C} /{ }^{15} \mathrm{~N}$-labeling, is the decreased relaxation times of protons in RNAs with reduced proton spin density. In addition, any ${ }^{13} \mathrm{C}$ atoms attached to deuterium will have better relaxation properties with respect to the ${ }^{13} \mathrm{C}-{ }^{1} \mathrm{H}$ moieties, and ${ }^{13} \mathrm{C}-{ }^{13} \mathrm{C}$ transfers are more efficient (Dayie et al., 1998). Therefore, specific deuterium labeling should greatly aid in the study of larger RNA molecules. Two protocols have been published for specific deuterium labeling. One uses a combination chemical/enzymatic synthesis approach (Tolbert and Williamson, 1996), while the other uses all chemical synthesis (Foldesi et al., 1992, 1996; Glemarec et al., 1996). Figure 7.7.8 shows an example of the filtering affect on a NOESY spectrum of specific deuterium labeling of a 30-nucleotide RNA at the $3^{\prime}, 4^{\prime}, 5^{\prime}$, and $5^{\prime \prime}$ positions of the ribose ring (Tolbert and Williamson, 1996). In addition to the reduction in overlap, the relaxation times of the remaining protons in the proton-depleted environment were increased $\sim 2$-fold. The disadvantage of deuterium labeling is the greatly reduced ${ }^{1} \mathrm{H}^{-1} \mathrm{H}$ NOE-based information content essential for the structure determination. These disadvantages may in part be compensated because high degrees of deuteration allow longer NOESY mixing times to be used (>150 msec), since potential spin diffusion pathways are limited. This possibly extends the observable ${ }^{1} \mathrm{H}-{ }^{1} \mathrm{H}$ distance in NOESY experiments to $\sim 7 \AA$, thus adding rare long-range information for the structure determination, as has been shown for highly deuterated proteins. It is also possible, however, to make multiple samples with different deuteration patterns to circumvent this problem (Tolbert and Williamson, 1996). Alternatively, since many of the NOEs between the base and sugar protons that define the conformation of the helices are redundant, the reduced NOE data set from one specific deuteration pattern may still be useful for determining qualitative structural models of larger RNAs.

A number of protons involved in relevant interactions in nucleic acids are often not observable due to exchange processes. An experimental approach to improving the sensitivity of
NOEs to amino protons in RNA has been developed (Krishnan and Rance, 1995; Mueller et al., 1995). As was noted above, similar concepts have also been utilized to improve the sensitivity of through-bond experiments for assignment of base amino protons (Simorre et al., 1995, 1996b). Easier assignment and identification of amino proton NOEs, which are often difficult to observe, has the potential to greatly increase the quality of structure determinations. This is particularly true for RNA-protein interactions, since amino protons line the grooves where proteins often make specific contacts. RNA structure tends to be very dynamic and flexible, and it is very common to observe NMR resonances that are broadened by conformational exchange.

\section{HYDROGEN BONDS IN RNA NMR STRUCTURES}

Some of the most important interactions within RNA structures are hydrogen bonding interactions. These can now be directly determined unambiguously by NMR even in the case of the noncanonical base-pairing interactions that are the most biologically interesting and novel aspects of RNA structure. The existence of scalar couplings due to hydrogen bonds between imino proton donors and acceptor nitrogens in Watson-Crick base-pairs of RNA was recently shown (Dingley and Grzesiek, 1998). Hydrogen bonds have a partially covalent character that gives rise to scalar spin-spin couplings of the ${ }^{2 \mathrm{~h}} \mathrm{~J}_{\mathrm{NN}}$ and ${ }^{1 \mathrm{~h}} \mathrm{~J}_{\mathrm{HN}}$ type, which are an important additional NMR parameter for the structure determination of biomacromolecules in solution. In early stages of a structural study, these HNN-COSY-type experiments allow the rapid identification of basic secondary structural elements such as A-form Watson-Crick duplexes in RNA. The imino resonances of base-paired guanosines and uridines can be directly correlated with their acceptor nitrogens, $\mathrm{N} 3$ for cytosines and N1 for adenines, respectively, as shown in Figure 7.7.9. The corresponding ${ }^{2 \mathrm{~h}} \mathrm{~J}_{\mathrm{NN}}$ coupling constant values across the hydrogen bonds are surprisingly large and on the order of $6 \mathrm{~Hz}$ (Dingley and Grzesiek, 1998; Pervushin et al., 1998a). Before the recent advance in measuring these scalar couplings, it was only possible to obtain indirect evidence for Watson-Crick base pairing in the A-form helix by the observation of upfield-shifted imino resonances, along with a network of cross-strand NOEs indicative of a typical base pair.
Biophysical Analysis of Nucleic Acids 


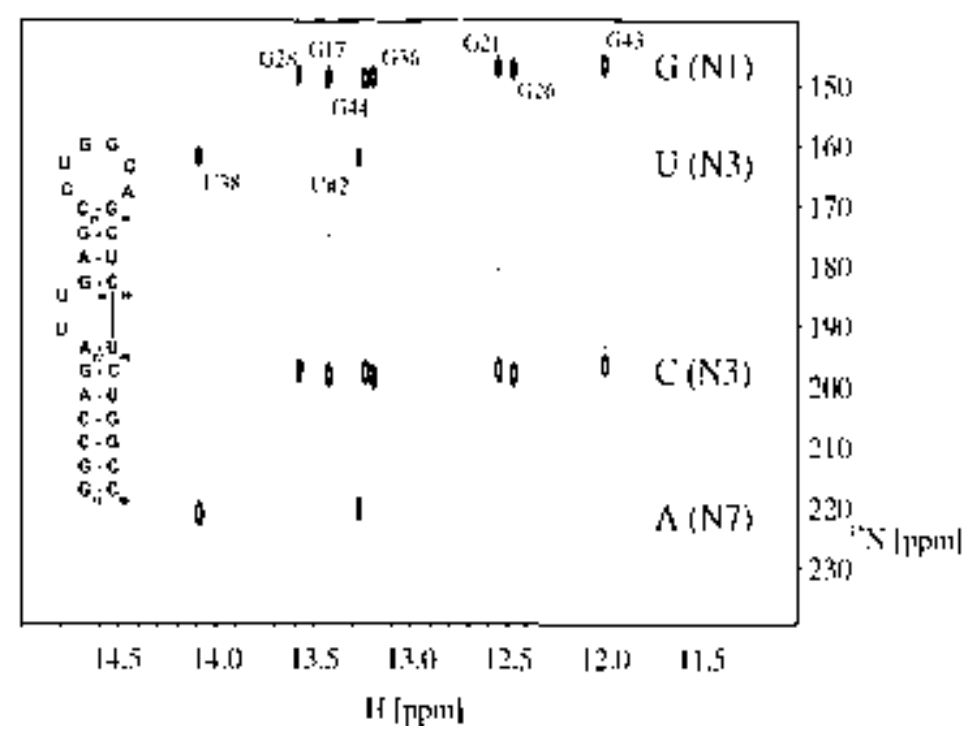

Figure 7.7.9 Direct observation of scalar cross-hydrogen bond ${ }^{2 h} J_{N N}$ coupling constants in the

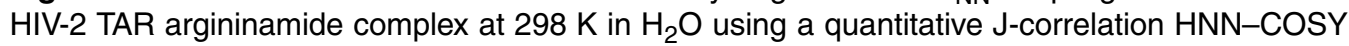
experiment. Assignments for all observable imino resonances that are involved in Watson-Crick base pairs in HIV-2 TAR are given. Sequence and secondary structure of HIV-2 TAR is shown. The sequence is identical to HIV-1 TAR except for the deletion of the C24 bulge nucleotide.

Unfortunately, some hydrogen bonding interactions are difficult to observe due to rapid imino proton exchange; however, a modified pulse scheme allows the observation of ${ }^{2 \mathrm{~h}} \mathrm{~J}_{\mathrm{NN}}$ couplings in the absence of detectable imino protons (Hennig and Williamson, 2000). Instead of measuring the coupling by detection of the imino protons, the ${ }^{2 \mathrm{~h}} \mathrm{~J}_{\mathrm{NN}}$ couplings can be observed via ${ }^{2} \mathrm{~J}_{\mathrm{HN}}$ correlations with nonexchangeable base protons. The experiment provides a sensitive measure of base-pairing interactions, even in $\mathrm{D}_{2} \mathrm{O}$ solution. This approach has led to the conformation of the existence of the U38.A27.U23 base triple in the HIV-2 transactivation response element (TAR)-argininamide complex as shown in Figure 7.7.10. Additionally, the chemical shifts of the unprotonated base nitrogens, which can be correlated to nonexchangeable aromatic protons $\mathrm{via}^{2} \mathrm{~J}_{\mathrm{HN}}$ couplings in a reasonably sensitive manner, might be useful to identify hydrogen-bonding interactions (Sklenar et al., 1994).

Crystal structures of two different ribozymes have highlighted the important structural role of 2'-OHs (Pley et al., 1994a; Scott et al., 1995; Cate et al., 1996). Only a handful of 2 '-OH protons have been observed by NMR, thus making any direct evidence for hydrogen bonding difficult (Allain and Varani, 1995). However, hydrogen-bonding interactions have been proposed based on a large number of NOEs in the region which localize possible hydrogen bond acceptor and donor groups near the $2^{\prime}-\mathrm{OH}$, as in the GNRA structures (where $\mathrm{N}$ is any nucleotide and $\mathrm{R}$ is a purine; Jucker et al., 1996). One additional consideration is suggested by the paromomyin-16S RNA structure, where some potential interactions appeared with heavy atom distances in the 4.0 to $4.5 \AA$ range (Fourmy et al., 1996). This distance is generally considered too long for a hydrogen bond, but could possibly be due to a water-mediated hydrogen bond. These types of interactions are very difficult to determine even in protein NMR, where large hydrophobic cores help protect single water molecules from exchanging with the bulk solvent (Otting and Wüthrich, 1989b; Otting et al., 1991). The structural role of 2'-OHs and water molecules in RNA structure will be an important area of future investigations.

\section{MEASUREMENT OF BACKBONE TORSIONS}

Many of the interesting RNA structures studied exhibit a wide variety of backbone conformations, suggesting that torsion restraints will be important to define RNA structure. RNA backbone conformations are characterized by six backbone torsion angles $(\alpha, \beta$, $\gamma, \delta, \varepsilon, \zeta)$ as illustrated in Figure 7.7.11. NMR analysis of the backbone conformation is complicated by the lack of useful ${ }^{1} \mathrm{H}-{ }^{1} \mathrm{H}$ NOE distance restraints available that define the back- 


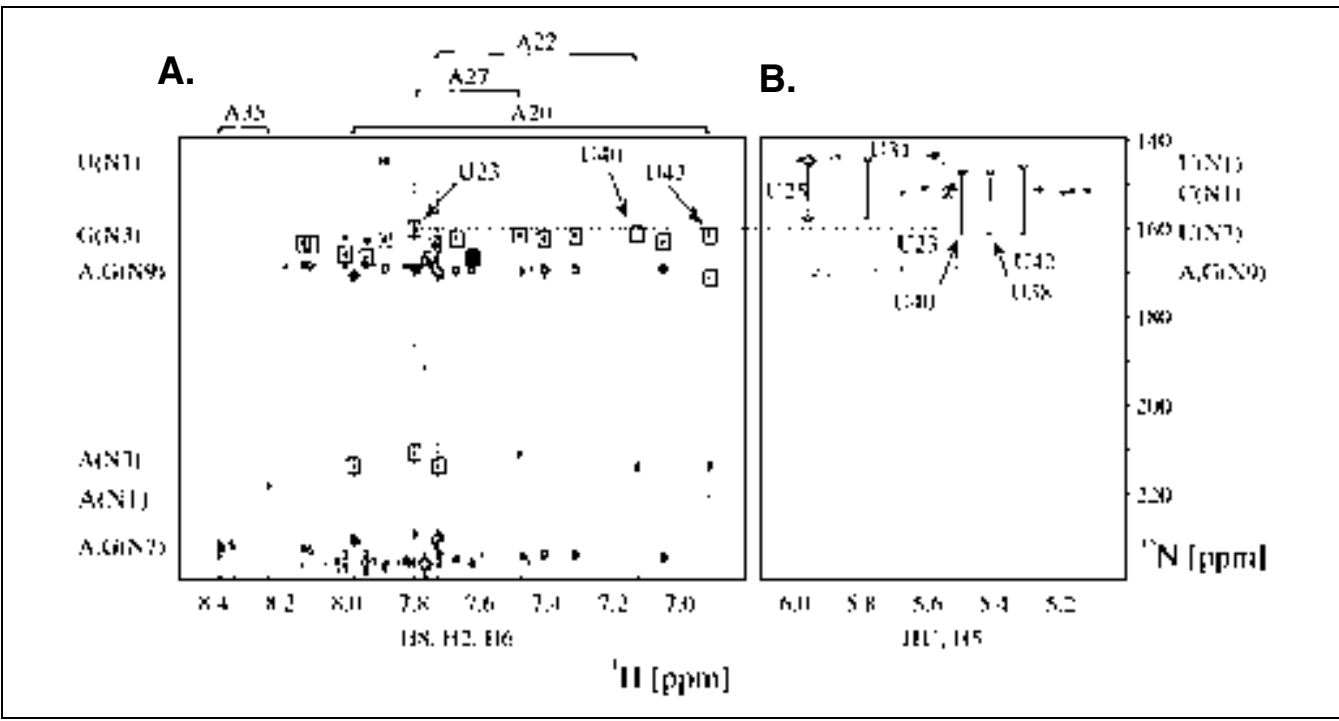

Figure 7.7.10 Direct observation of scalar cross-hydrogen bond ${ }^{2 h} \mathrm{~J}_{\mathrm{NN}}$ and intraresidue ${ }^{2} \mathrm{~J}_{\mathrm{NN}}$ coupling constants in the HIV-2 TAR argininamide complex at $298 \mathrm{~K}$ in $\mathrm{D}_{2} \mathrm{O}$. (A) Quantitative $\mathrm{J}$-correlation ${ }^{2} \mathrm{~J}_{\mathrm{HN}} \mathrm{HNN}$-COSY spectrum. Assignments for all adenosine residues in HIV-2 TAR are given on top of the spectrum. The corresponding $\mathrm{H} 2$ and $\mathrm{H} 8$ proton resonance frequencies are highlighted by vertical wide and narrow dotted lines, respectively. Cross-peaks that are due to ${ }^{2} J_{N N}$ couplings have opposite signs and are shown in boxes. A dashed horizontal line connects the N3 resonance frequency of $U 23$ as obtained from (A) ${ }^{2} J_{H N} H N N-C O S Y$ and $(B){ }^{n} J_{H N} H M Q C$ experiments. Arrows point to the A20-U42 Watson-Crick base-pair correlation, the A22-U40 correlation, and the A27-U23 correlation at the $\mathrm{H} 8$ proton resonance frequency of $\mathrm{A} 27$. Chemical shift regions for the nitrogen and proton resonances giving rise to the observable correlations are given next to the corresponding axis. Peaks marked with an asterisk are due to minor impurities from sample degradation. (B) Identification of cross-hydrogen bond coupling partners using intraresidual ${ }^{n} J_{H N}$ HMQC correlations. Assignments for all uridine residues in HIV-2 TAR are given. Connectivities for uridine residues are due to small intraresidue couplings $\left({ }^{3} \mathrm{~J}_{\mathrm{H} 5 \mathrm{~N} 1} \approx 4.5 \mathrm{~Hz},{ }^{3} \mathrm{~J}_{\mathrm{H} 5 \mathrm{~N} 3} \approx 2.5 \mathrm{~Hz}\right)$. The corresponding H5,N1 and H5,N3 cross-peaks are connected by vertical solid lines. Chemical shift regions for the nitrogen and proton resonances giving rise to the observable correlations are given next to the corresponding axis.

bone torsions. Alternatively, vicinal ${ }^{3} \mathrm{~J}$ coupling constants can provide useful structural information about torsion-angle conformations (Wijmenga and van Buuren, 1998; Marino et al., 1999). Vicinal ${ }^{3} \mathrm{~J}$ couplings, involving nuclei separated by three bonds, can be correlated to torsion angles using empirical Karplus relations (Karplus, 1959). With the introduction of isotopic labeling methods, a number of approaches have been developed that take advantage of both ${ }^{1} \mathrm{H}_{-}{ }^{31} \mathrm{P}$ and ${ }^{13} \mathrm{C}-{ }^{31} \mathrm{P}$ couplings to measure these torsion angle restraints. Additionally, the ribose sugar pucker as well as the glycosidic torsion angle $\chi$ as shown in Figure 7.7.11 can be characterized utilizing vicinal ${ }^{1} \mathrm{H}-{ }^{1} \mathrm{H}$ and ${ }^{13} \mathrm{C}-{ }^{1} \mathrm{H}$ couplings.

\section{Sugar Pucker and the $\delta$ Torsion}

The ribose sugar geometry is defined by five alternating torsion angles $\left(v_{0}\right.$ through $v_{4}$, see Fig. 7.7.11). Usually, the ribose sugar adopts one of the energetically preferred $\mathrm{C}^{\prime}$-endo (South) or the C3'-endo (North) conforma- tions. A number of ${ }^{1} \mathrm{H},{ }^{1} \mathrm{H}$ and ${ }^{1} \mathrm{H},{ }^{13} \mathrm{C}$ scalar couplings are available to determine the sugar pucker qualitatively, with a combination of $\mathrm{H} 1^{\prime}-\mathrm{H} 2^{\prime}$ and $\mathrm{H} 3^{\prime}-\mathrm{H} 4^{\prime}$ coupling constants being the most useful for smaller RNAs. The ${ }^{3} \mathrm{~J}_{\mathrm{H} 1^{\prime} \mathrm{H} 2^{\prime}}$ vicinal coupling is $>8 \mathrm{~Hz}$ for $\mathrm{C}^{2}$-endo puckers and $\sim 1 \mathrm{~Hz}$ for the $\mathrm{C}^{\prime}$-endo puckers, typically found in A-form helices. The opposite behavior is expected for the ${ }^{3} \mathrm{~J}_{\mathrm{H}^{\prime} \mathrm{H}^{\prime}}$ coupling constant with $\mathrm{C} 2^{\prime}$-endo puckers associated with small and the $\mathrm{C} 3$ '-endo puckers associated with relatively large coupling constant values. The easiest method to measure the $\mathrm{H}^{\prime}, \mathrm{H}^{\prime} / \mathrm{H}^{\prime}{ }^{\prime}, \mathrm{H} 4^{\prime}$ coupling constant is through the use of 2-D ${ }^{1} \mathrm{H}-{ }^{1} \mathrm{H}$ COSY experiments (Varani and Tinoco, 1991). The absence of a $\mathrm{H}^{\prime}, \mathrm{H} 2^{\prime} \mathrm{COSY}$ crosspeak is often qualitatively interpreted as the C3'-endo conformation; however, this approach may be misleading where broad lines lead to the cancellation of the antiphase crosspeaks. This pitfall, which becomes more and more important with increasing molecular weights associated with line-broadening ef-
Biophysical Analysis of Nucleic Acids 


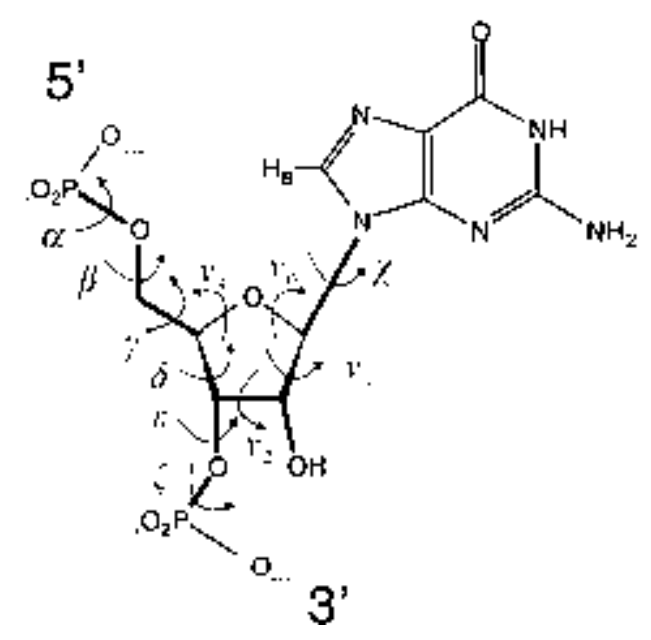

Figure 7.7.11 The six backbone torsion angles are shown on a segment of RNA. Individual torsion

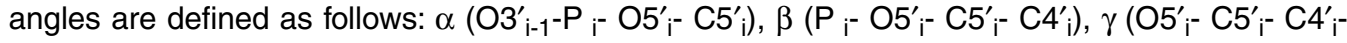

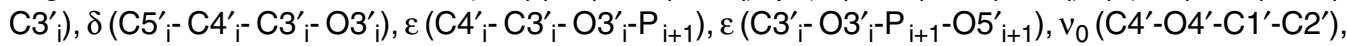
$v_{1}\left(\mathrm{O}^{\prime}-\mathrm{C} 1^{\prime}-\mathrm{C} 2^{\prime}-\mathrm{C} 3^{\prime}\right), v_{2}\left(\mathrm{C}^{\prime}-\mathrm{C} 2^{\prime}-\mathrm{C}^{\prime}-\mathrm{C} 4^{\prime}\right), v_{3}\left(\mathrm{C}^{\prime}-\mathrm{C}^{\prime}-\mathrm{C}^{\prime}-\mathrm{O} 4^{\prime}\right), v_{3}\left(\mathrm{C}^{\prime}-\mathrm{C}^{\prime}-\mathrm{O} 4^{\prime}-\mathrm{C} 1^{\prime}\right), \chi$ (pyrimid-

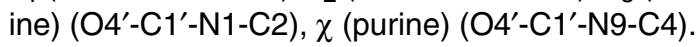

fects, can be avoided with the use of the $\mathrm{HCCH}$ E.COSY (exclusive correlation spectroscopy) experiment (Schwalbe et al., 1994), where even small ${ }^{1} \mathrm{H}-{ }^{1} \mathrm{H}$ couplings can be measured. This experiment will also be adversely affected by broad lines, but because the measurement is not based on the absence of a peak, a more definitive measurement is possible. In the presence of severe spectral crowding, the HCCE.COSY-CCH TOCSY experiment, a variant which contains a TOCSY period to transfer magnetization to the well-resolved $\mathrm{C1}^{\prime}$, improves the spectral dispersion (Schwalbe et al., 1995; Glaser et al., 1996). An alternative method involves a collection of ${ }^{1} \mathrm{H}-{ }^{13} \mathrm{C}$ coupled HMQC-NOESY and HMQC-TOCSY spectra that are collected such that the sign of a number of ${ }^{2} \mathrm{~J}_{\mathrm{CH}}$ and ${ }^{3} \mathrm{~J}_{\mathrm{CH}}$ couplings can be determined and used to define the sugar pucker as shown in Table 7.7.3 (Hines et al., 1994). Often ribose groups are found with homonuclear $\mathrm{H}^{\prime}, \mathrm{H}^{\prime} / \mathrm{H} 3^{\prime}, \mathrm{H} 4^{\prime}$ coupling constants in the 3 to $6 \mathrm{~Hz}$ range, indicative of a conformation in between the $\mathrm{C} 2^{\prime}$-endo and $\mathrm{C}^{\prime}$-endo puckers. This mixed conformation is often left unrestrained, since it is averaging between the two major conformations (Aboul-ela et al., 1995; Brodsky and Williamson, 1997).

\section{$\chi$ Torsion}

Two heteronuclear vicinal ${ }^{1} \mathrm{H},{ }^{13} \mathrm{C}$ couplings contain useful information about the glycosidic torsion angle $\chi$. The ${ }^{3} \mathrm{~J}_{\mathrm{H}^{\prime} \mathrm{C}}$ couplings involving the $\mathrm{C} 4, \mathrm{C} 8$ carbons in purines and the $\mathrm{C} 2, \mathrm{C} 6$ carbons in pyrimidines, respectively, all depend on the $\chi$ torsion. The preferred orientation around $\chi$ in A-form helix is anti, which makes the base accessible for commonly found hydrogen-bonding interactions. The adopted conformation in RNA around $\chi$ strongly depends on the corresponding sugar pucker with the $\mathrm{C}^{\prime}$ endo puckers associated with the anti orientation. However, the different anti and syn conformations around the glycosidic torsion can usually be identified on the basis of intraresidual sugar-to-base, H1-3'-H8/H6, NOEs. The distance between $\mathrm{H}^{\prime}{ }^{\prime}$ and $\mathrm{H} 8 / \mathrm{H} 6$ is shorter in the syn conformation, a corresponding strong $\mathrm{NOE}$ indicative for such a conformation.

\section{$\varepsilon$ and $\beta$ Torsions}

Considering the torsion angle $\beta$, the three low-energy staggered rotamers are characterized by a unique combination of vicinal ${ }^{1} \mathrm{H},{ }^{31} \mathrm{P}$ and ${ }^{13} \mathrm{C},{ }^{31} \mathrm{P}$ couplings. In a standard A-form helix, $\beta$ is in the trans conformation ( $\beta$ $=180^{\circ}$ ) for which the ${ }^{3} \mathbf{J}_{\mathrm{PH} 5^{\prime}}$ and ${ }^{3} \mathbf{J}_{\mathrm{PH} 5^{\prime \prime}}$ are small and the ${ }^{3} \mathrm{~J}_{\mathrm{PC} 4^{\prime}}$ and ${ }^{3} \mathrm{~J}_{\mathrm{PH} 4^{\prime}}$ are large, as summarized in Table 7.7.3. Therefore, when one of the two ${ }^{3} \mathbf{J}_{\mathrm{PH} 5}$ couplings is large, a gauche conformation $\left(\beta= \pm 60^{\circ}\right)$ is present. This analysis of ${ }^{3} \mathrm{~J}_{\mathrm{PH} 5}$ couplings can also easily indicate the presence of conformational averaging as found in the HIV-2 TAR-argininamide complex where one of the nucleotides exhibited large couplings for both the ${ }^{3} \mathbf{J}_{\mathrm{PH} 5^{\prime}}$ and ${ }^{3} \mathbf{J}_{\mathrm{PH} 5^{\prime \prime}}$ (Brodsky and Williamson, 1997). A similar qualitative analysis exists for the $\varepsilon$ torsion and associated staggered rotamers, which can be measured by monitoring the ${ }^{3} \mathrm{~J}_{\mathrm{C} 4^{\prime} \mathrm{P}},{ }^{3} \mathrm{~J}_{\mathrm{C} 2^{\prime} \mathrm{P}}$, and ${ }^{3} \mathrm{~J}_{\mathrm{H} 3^{\prime} \mathrm{P}}$ 
couplings. However, the ${ }^{3} \mathrm{~J}_{\mathrm{H} 3^{\prime} \mathrm{P}}$ coupling does not change significantly for the different conformations and shows small values for both the trans $\left(\varepsilon=180^{\circ}\right)$ and the gauche ${ }^{-}\left(\varepsilon=-60^{\circ}\right)$ conformers. Thus, in order to unambiguously define $\varepsilon$, the ${ }^{3} \mathrm{~J}_{\mathrm{C} 4}$ P and ${ }^{3} \mathrm{~J}_{\mathrm{C} 2}$ P need to be analyzed. The $\varepsilon$ torsion is in the trans conformation in a standard A-form helix where the ${ }^{3} \mathrm{~J}_{\mathrm{C} 2} \mathrm{P}$ coupling is small and the ${ }^{3} \mathrm{~J}_{\mathrm{C} 4}$ P coupling is large, as summarized in Table 7.7.3.

The $\varepsilon$ and $\beta$ torsions can be determined by measuring a variety of ${ }^{13} \mathrm{C},{ }^{31} \mathrm{P}$ and ${ }^{1} \mathrm{H},{ }^{31} \mathrm{P}$ scalar couplings. Some of these torsions may be measured directly in 2-D ${ }^{1} \mathrm{H},{ }^{31} \mathrm{P}$ heteronuclear COSY (HETCOR) experiments (Sklenar et al., 1986) and nonrefocused ${ }^{1} \mathrm{H},{ }^{31} \mathrm{P}$ HSQCs if the phosphorus and proton resonances are sufficiently resolved; however, both the ribose proton and phosphorus resonances involved are generally overlapped for even moderate-sized RNAs. Accurate measurements for ${ }^{13} \mathrm{C},{ }^{31} \mathrm{P}$ and ${ }^{1} \mathrm{H},{ }^{31} \mathrm{P}$ couplings can be obtained from both phosphorus fitting of doublets from singlets (so called P-FIDS) (Schwalbe et al., 1993) or spin echo difference experiments (Legault et al., 1995; Hoogstraten and Pardi, 1998b; Szyperski et al., 1999). An extensive strategy has been introduced based on the intensity of cross-peaks in 3-D HCP and HPCH experiments (Varani et al., 1995). The intensity of cross-peaks in these spectra are proportional to the ${ }^{3} \mathbf{J}_{\mathrm{PH} 5},{ }^{3} \mathbf{J}_{\mathrm{PH}^{\prime} 5^{\prime \prime}}$, and ${ }^{3} \mathbf{J}_{\mathrm{PC} 4}$ couplings. This approach suffers from the potential drawback that peak intensities may also be affected by other factors, such as dynamics. Recently, novel experiments for the measurement of ${ }^{13} \mathrm{C},{ }^{31} \mathrm{P}$ and ${ }^{1} \mathrm{H},{ }^{31} \mathrm{P}$ couplings using intensity modulations of cross-peaks due to coupling constant evolution in so-called quantitative $\mathbf{J}$ correlations have been introduced (Clore et al., 1998; Richter et al., 1998).

\section{$\gamma$ Torsion}

Measurement of the $\gamma$ torsion is difficult due to the need for stereospecific assignments of the $\mathrm{H}^{\prime}$ and $\mathrm{H}^{\prime \prime}$ proton resonances. The twobond $\mathrm{C}^{\prime}, \mathrm{H} 5^{\prime} / \mathrm{H} 5^{\prime \prime}$ couplings can be used in conjunction with the vicinal $\mathrm{H} 4^{\prime}, \mathrm{H} 5^{\prime} / \mathrm{H} 5^{\prime \prime}$ couplings to define $\gamma$ (Hines et al., 1994; Schwalbe et al., 1994). Some couplings may be obtained from a collection of ${ }^{1} \mathrm{H},{ }^{13} \mathrm{C}$ coupled versions of 3-D ${ }^{13} \mathrm{C}$-edited TOCSY and NOESY spectra (Hines et al., 1993, 1994). Unfortunately, both the $\mathrm{C}^{\prime}{ }^{\prime}$ and the $\mathrm{H}^{\prime}$ ' in A-helical RNAs are extremely crowded, making correlations from these to the $\mathrm{C}^{\prime} / \mathrm{H} 5^{\prime}$ region, also showing poor dispersion, difficult. Therefore, experiments similar to the HCC-E.COSY-CCH TOCSY, where the overlapped $\mathrm{H} 4^{\prime}-\mathrm{H} 5^{\prime}$ cross-peaks are correlated to the $\mathrm{C} 1^{\prime} / \mathrm{H}^{\prime}$, may be particularly useful if sufficient TOCSY transfer can be achieved (Schwalbe et al., 1994). In A-form helices, both the ${ }^{3} \mathbf{J}_{\mathrm{H} 4^{\prime} \mathrm{H} 5^{\prime}}$ and ${ }^{3} \mathbf{J}_{\mathrm{H} 4^{\prime} \mathrm{H} 5^{\prime \prime}}$ scalar couplings are small in the preferred staggered gauche $^{+}\left(\gamma=60^{\circ}\right)$ conformation. Table 7.7.3 indicates that when $\gamma$ changes to gauche $e^{-}(\gamma=$ $\left.-60^{\circ}\right)$ or trans $\left(\gamma=180^{\circ}\right)$ conformations, either the ${ }^{3} \mathrm{~J}_{\mathrm{H} 4^{\prime} \mathrm{H} 5^{\prime}}$ or ${ }^{3} \mathrm{~J}_{\mathrm{H} 4^{\prime} \mathrm{H} 5^{\prime \prime}}$ coupling becomes larger; however, additional information is required to determine the stereospecific assignment. The

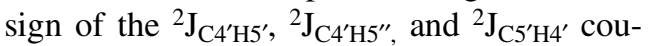
plings are very useful to help determine not only the stereospecific assignments but also the conformation as summarized in Table 7.7.3.

\section{$\alpha$ and $\zeta$ torsions}

Unfortunately, the $\alpha$ and $\zeta$ torsions are not accessible by J-coupling measurements because the involved ${ }^{16} \mathrm{O}$ nuclei have no magnetic moment. Some groups have used ${ }^{31} \mathrm{P}$ or ${ }^{13} \mathrm{C}$ chemical shifts as a guide for loose constraints on these torsions; however, the correlation between ${ }^{31} \mathrm{P}$ chemical shifts and the phosphodiester backbone conformation is not well understood in RNA. For example, in tRNA, a wide range of phosphorus chemical shifts are observed that are outside the ranges expected for variation of the $\alpha$ or $\zeta$ torsions, and other factors may be major contributors to phosphorous chemical shifts (Gueron and Shulman, 1975; Gorenstein and Luxon, 1979; Salemink et al., 1979). Furthermore, quantum calculations have shown that counterions also affect the chemical shift, further indicating that ${ }^{31} \mathrm{P}$ chemical shifts may not be a reliable indicator of the conformation (Giessner-Prettre and Pullman, 1987). The understanding of different conformational contributions to the investigated $\mathrm{C}^{\prime}, \mathrm{C}^{\prime}$, and $\mathrm{C}^{\prime}{ }^{13} \mathrm{C}$ chemical shifts remains incomplete (Xu et al., 1998); however, the use of heteronuclear chemical shifts in RNA structure calculations might have a greater impact in the future, especially in regions with low density of traditional restraints such as distances and torsion angles. Until a more complete chemical shift data base is created, restraints based on chemical shifts alone should probably be used with great caution.

\section{The Value of Torsion Restraints in Structure Determination}

In protein NMR, torsion restraints help increase the precision of the structure, and it is expected that the precision of nucleic acid structures will also improve with the inclusion
Biophysical Analysis of Nucleic Acids 
Table 7.7.3 Backbone J-Couplings in RNA

\begin{tabular}{|c|c|c|c|}
\hline Angle & Rotamer & ${ }^{\mathrm{n} J}-$ Coupling & $\mathrm{J}(\mathrm{Hz})$ \\
\hline \multirow[t]{10}{*}{$\beta$} & trans $^{a}$ & H5' - P(i) & $1-4$ \\
\hline & & $\mathrm{H} 5^{\prime \prime}-\mathrm{P}(\mathrm{i})$ & $1-3$ \\
\hline & & $\mathrm{H} 4^{\prime}-\mathrm{P}(\mathrm{i})^{b}$ & $\sim 2$ \\
\hline & & $\mathrm{C} 4^{\prime}-\mathrm{P}(\mathrm{i})$ & $8-11$ \\
\hline & gauche ${ }^{-}$ & $\mathrm{H} 5^{\prime}-\mathrm{P}(\mathrm{i})$ & $1-3$ \\
\hline & & $\mathrm{H} 5^{\prime \prime}-\mathrm{P}(\mathrm{i})$ & $>15$ \\
\hline & & $\mathrm{C} 4^{\prime}-\mathrm{P}(\mathrm{i})$ & $<5$ \\
\hline & gauche ${ }^{+}$ & $\mathrm{H} 5^{\prime}-\mathrm{P}(\mathrm{i})$ & $>15$ \\
\hline & & $\mathrm{H} 5^{\prime \prime}-\mathrm{P}(\mathrm{i})$ & $1-3$ \\
\hline & & $\mathrm{C} 4^{\prime}-\mathrm{P}(\mathrm{i})$ & $<5$ \\
\hline \multirow[t]{11}{*}{$\varepsilon$} & $\operatorname{trans}^{a}$ & $\mathrm{H} 3^{\prime}-\mathrm{P}(\mathrm{i}+1)$ & $<5$ \\
\hline & & $\mathrm{C} 2^{\prime}-\mathrm{P}(\mathrm{i}+1)$ & $<5$ \\
\hline & & $\mathrm{C} 4^{\prime}-\mathrm{P}(\mathrm{i}+1)$ & $>10$ \\
\hline & gauche ${ }^{-}$ & $\mathrm{H} 3^{\prime}-\mathrm{P}(\mathrm{i}+1)$ & $<5$ \\
\hline & & $\mathrm{H} 2^{\prime}-\mathrm{P}(\mathrm{i}+1)^{c}$ & $2-3$ \\
\hline & & $\mathrm{C} 2^{\prime}-\mathrm{P}(\mathrm{i}+1)$ & $>10$ \\
\hline & & $\mathrm{C} 4^{\prime}-\mathrm{P}(\mathrm{i}+1)$ & $<5$ \\
\hline & gauche $^{+}$ & $\mathrm{H} 3^{\prime}-\mathrm{P}(\mathrm{i}+1)$ & $>15$ \\
\hline & & $\mathrm{H} 2^{\prime}-\mathrm{P}(\mathrm{i}+1)^{\mathrm{c}}$ & $2-3$ \\
\hline & & $C 2^{\prime}-P(i+1)$ & $<5$ \\
\hline & & $\mathrm{C} 4^{\prime}-\mathrm{P}(\mathrm{i}+1)$ & $<5$ \\
\hline \multirow[t]{15}{*}{$\gamma^{d}$} & gauche $^{+a}$ & $\mathrm{H} 4^{\prime}-\mathrm{H} 5^{\prime}$ & $1-3$ \\
\hline & & $\mathrm{H} 4^{\prime}-\mathrm{H} 5^{\prime \prime}$ & 3 \\
\hline & & $\mathrm{C} 4^{\prime}-\mathrm{H} 5^{\prime}$ & - \\
\hline & & $\mathrm{C} 4-\mathrm{H} 5^{\prime \prime}$ & + \\
\hline & & $\mathrm{C}^{\prime}-\mathrm{H} 4^{\prime}$ & + \\
\hline & trans & $\mathrm{H} 4^{\prime}-\mathrm{H} 5^{\prime}$ & 3 \\
\hline & & $\mathrm{H} 4^{\prime}-\mathrm{H} 5^{\prime \prime}$ & $9-11$ \\
\hline & & $\mathrm{C} 4^{\prime}-\mathrm{H} 5^{\prime}$ & + \\
\hline & & $\mathrm{C} 4-\mathrm{H}^{\prime \prime}$ & - \\
\hline & & $\mathrm{C} 5^{\prime}-\mathrm{H} 4^{\prime}$ & - \\
\hline & gauche ${ }^{-}$ & $\mathrm{H} 4^{\prime}-\mathrm{H} 5^{\prime}$ & $9-11$ \\
\hline & & $\mathrm{H} 4^{\prime}-\mathrm{H} 5^{\prime \prime}$ & 5 \\
\hline & & $\mathrm{C} 4^{\prime}-\mathrm{H} 5^{\prime}$ & - \\
\hline & & $\mathrm{C} 4-\mathrm{H}^{\prime \prime}$ & - \\
\hline & & $\mathrm{C} 5^{\prime}-\mathrm{H} 4^{\prime}$ & - \\
\hline \multirow[t]{14}{*}{$\delta^{d}$} & $\mathrm{C}^{\prime}$ endo $^{a}$ & $\mathrm{H} 1^{\prime}-\mathrm{H} 2^{\prime}$ & $\sim 1$ \\
\hline & & $\mathrm{H} 2^{\prime}-\mathrm{H} 3^{\prime}$ & $\sim 4$ \\
\hline & & $\mathrm{H} 3^{\prime}-\mathrm{H} 4^{\prime}$ & $\sim 9$ \\
\hline & & $\mathrm{C} 1^{\prime}-\mathrm{H} 2^{\prime}$ & - \\
\hline & & $\mathrm{C} 2^{\prime}-\mathrm{H} 3^{\prime}$ & - \\
\hline & & $\mathrm{C} 3^{\prime}-\mathrm{H} 2^{\prime}$ & + \\
\hline & & $\mathrm{C}^{\prime}-\mathrm{H} 3^{\prime}$ & + \\
\hline & $\mathrm{C} 2^{\prime}$ endo & $\mathrm{H} 1^{\prime}-\mathrm{H} 2^{\prime}$ & $\sim 8$ \\
\hline & & $\mathrm{H} 2^{\prime}-\mathrm{H} 3^{\prime}$ & $\sim 4$ \\
\hline & & $\mathrm{H} 3^{\prime}-\mathrm{H} 4^{\prime}$ & $\sim 1$ \\
\hline & & $\mathrm{C} 1^{\prime}-\mathrm{H} 2^{\prime}$ & + \\
\hline & & $\mathrm{C} 2^{\prime}-\mathrm{H} 3^{\prime}$ & + \\
\hline & & $\mathrm{C} 3^{\prime}-\mathrm{H} 2^{\prime}$ & - \\
\hline & & $\mathrm{C} 4^{\prime}-\mathrm{H} 3^{\prime}$ & - \\
\hline
\end{tabular}

Recent Advances in RNA Structure Determination by NMR

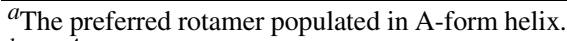

$b_{\mathrm{The}}{ }^{4} \mathrm{~J}_{\mathrm{H} 4^{\prime} \mathrm{P}}$ coupling can reach measurable values, $\sim 2 \mathrm{~Hz}$, if $\beta$ falls in the trans region and the corresponding torsion angle $\gamma$ adopts a gauche $e^{+}$conformation.

${ }^{c}$ The ${ }^{4} \mathrm{~J}_{\mathrm{H} 2}$ P coupling is $\sim 2$ to $3 \mathrm{~Hz}$, if $\varepsilon$ adopts a gauche conformation.

$d_{\text {The characteristic sign patterns of involved }}^{2} \mathrm{~J}_{\mathrm{HC}}$ couplings contain particulary useful information to restrict either the torsion $\gamma$ or the sugar pucker.
} 
of torsion restraints. J-coupling restraints can be implemented in two different ways during the structure determination. They can be introduced qualitatively by restricting a torsion angle in a loose manner $\left( \pm 30^{\circ}\right)$ to one of the three staggered rotamers along the phosphodiester backbone or defining the preferred ribose sugar pucker such as $\mathrm{C} 2{ }^{\prime}$-endo or $\mathrm{C} 3^{\prime}$-endo. Alternatively, vicinal J-couplings can be quantitatively related to a certain torsion angle using parameterized Karplus relations (Karplus, 1959; Wijmenga and van Buuren, 1998; Marino et al., 1999). Preliminary studies indicate that only mild improvement is obtained with sufficiently large distance restraint data sets (Allain and Varani, 1995; Brodsky and Williamson, 1997). In fact, in the absence of any torsion restraints other than the sugar puckers, a structure with a root mean square deviation (rmsd) to the average of $\sim 1.2 \AA$ can be defined with a large NOE restraint set for a 30-nucleotide RNA (Brodsky and Williamson, 1997). Inclusion of additional torsion restraints results in a modest improvement of the rmsd to $\sim 1.1 \AA$. Therefore, with a sufficient number of NOEs the structure may be reasonably well defined without torsion restraints that are increasingly difficult to measure for larger RNAs and RNA-protein complexes.

\section{NOVEL PARAMETERS FOR LIQUID-STATE NMR STRUCTURE DETERMINATION}

In general, there is a practical difficulty in defining RNA structures precisely by NMR because NOE- and J-coupling-based structure calculation relies on either short-range distance ( $<6 \AA$ ) or local torsion angle information. Thus, RNAs often are elongated structures, that are better approximated as cylindrical rather than globular shapes. There is a lack of NOE information between distant ends of the molecule and, as a result, the relative orientations of helical segments at opposite ends of the molecule are poorly defined. There have been two recent advances in methodology that may help alleviate or overcome this shortcoming.

\section{Relative Orientations of Bond Vectors Derived from Cross-Correlated Relaxation}

Cross-correlated relaxation rates have been recently introduced to high-resolution NMR as a tool for structure determination (Reif et al., 1997). For RNAs, these rates are measured using an experiment that belongs to the $\mathrm{HCCH}$ class, and result in the precise determination of the ribose sugar pucker without the need of any empirical Karplus parameterization (Felli et al., 1999). For example, measurement of cross-correlated relaxation rates between neighboring ${ }^{13} \mathrm{C}-{ }^{1} \mathrm{H}$ dipoles within the ribose ring can be used to define the sugar pucker. The efficiency of cross-correlated relaxation in this case depends on $1 / 2\left(3 \cos ^{2} \theta-1\right)$, where $\theta$ is the projection angle between the two ${ }^{13} \mathrm{C}-{ }^{1} \mathrm{H}$ bond vectors. Thus, cross-correlated relaxation is most efficient for either a parallel $\left(\theta=180^{\circ}\right)$ or an orthogonal $\left(\theta=90^{\circ}\right)$ orientation of the two interactions and can also be zero in the case of $\theta \sim 54.6^{\circ}$. The angle between ${ }^{13} \mathrm{C}-{ }^{1} \mathrm{H}$ bond vectors can be readily determined from $\mathrm{HCCH}-$ type cross-correlated relaxation measurements, and the resolution of this experiment can be further enhanced by combination with a CC-TOCSY transfer (Richter et al., 1999). The quantitative analysis of scalar J-couplings, especially in the case of homonuclear ${ }^{3} \mathrm{~J}_{\mathrm{HH}}$ couplings related to the ribose sugar pucker, becomes more and more difficult with increasing molecular weight. In contrast, the efficiency of cross-correlated relaxation pathways scales linearly with the overall correlation time of the molecule, which is related to its size. These new methods that exploit cross-correlated relaxation as a tool for structure determination should allow the characterization of conformations for larger RNA molecules, where J-coupling analysis is no longer feasible.

\section{Residual Dipolar Couplings as a Probe for Long-Range Interactions}

In isotropic solutions, molecules are randomly oriented such that all orientations of a molecule with respect to the external magnetic field are equally probable. Since molecules undergo rapid random Brownian motion, dipolar couplings are not directly observable in NMR spectra because they are averaged to zero. Over the past few years, methods have been developed to create a slightly anisotropic environment for molecules tumbling in solution. This results in a small degree of alignment of the molecule, and the dipolar couplings no longer average to zero, while retaining the quality of high-resolution NMR spectra. The most promising systems for NMR studies of partially aligned systems redilute liquid crystalline bicelles (Tjandra and Bax, 1997a) or bacteriophage solutions (Hansen et al., 1998a).

The reason for the preferred orientations of these macromolecules is interactions between the external magnetic field and orientation-dependent anisotropic magnetic susceptibility in
Biophysical Analysis of Nucleic Acids 
the molecules. The huge rod-like phages, as well as the disk-like liquid crystalline bicelles, populate the orientational space in a nonuniform manner, and can thus induce alignment of dissolved RNAs. Bicelles used in high-resolution NMR studies are composed of mixtures of phospholipids such as dimyristoylphosphatidylcholine (DMPC) and lipids with detergentlike properties such as dihexanoylphosphatidylcholine (DHPC). They form an anisotropic liquid crystalline phase when prepared at 10 to 30 weight $\%$ lipid in aqueous solution over the $20^{\circ}$ to $40^{\circ} \mathrm{C}$ range of temperatures (Prestegard, 1998). The filamentous phage Pf1 at concentrations between 10 and $60 \mathrm{mg} / \mathrm{L}$ also forms an aligned medium. The degree of alignment of the RNA molecule can be controlled by varying the concentration of the phage or bicelle solution. Higher phage or bicelle concentrations are associated with stronger alignments and produce larger residual dipolar couplings, while lower concentrations correspond to lower degrees of ordering, reflected in smaller dipolar couplings. There is a narrow useful range of alignments suitable for high-resolution NMR studies. Too much alignment gives larger dipolar couplings, but also results in line broadening to such an extent that high-resolution NMR is not possible.

Dipolar couplings on the order of \pm 10 to 30 $\mathrm{Hz}$ can be introduced using phages or bicelles as cosolutes. In particular, dipolar couplings contain valuable structural information for the evaluation of the relative orientations of helices in RNA molecules. The size of dipolar couplings for an axially symmetric RNA molecule depends on the average value of an orientational function, $1 / 2\left(3 \cos ^{2} \theta-1\right)$, and the inverse cubic distance, $1 / \mathrm{r}^{3}$, between the coupled nuclei. Here, the angle $\theta$ characterizes the axial orientation of the internuclear vector that connects the coupled nuclei with respect to the principal axis system of the molecular alignment tensor. For a directly bonded pair of nuclei with known distance, such as ${ }^{1} \mathrm{H}_{-13}{ }^{13}$ or ${ }^{1} \mathrm{H}^{-15} \mathrm{~N}$ in labeled RNA, angular restraints can be extracted from dipolar coupling data and incorporated during the structure calculation (Tjandra et al., 1997). Such one-bond dipolar couplings can be measured in a straightforward and sensitive manner. The difference between scalar J coupling constant values measured in isotropic and anisotropic media gives the residual dipolar coupling. The simplest method for the measurement of these large one-bond couplings is the HSQC experiments recorded without proton decoupling. Several methods to measure ${ }^{1} \mathrm{~J}_{\mathrm{HC}}$ or ${ }^{1} \mathrm{~J}_{\mathrm{HN}}$ more precisely have been published (Tjandra et al., 1996; Tjandra and Bax, 1997b).

In addition, dipolar ${ }^{1} \mathrm{H},{ }^{1} \mathrm{H}$ couplings are a potentially valuable source of long-range distance information (Hansen et al., 1998b). The transfer efficiency for dipolar couplings between protons falls off as a function of $1 / \mathrm{r}^{3}$ as opposed to the $1 / \mathrm{r}^{6}$ dependence of the NOE. Since those long-range interactions between dipolar coupled protons are obtainable in a straightforward manner, they can be measured using either COSY or TOCSY transfer schemes. Distances $>5$ A could be easily measured for a 16-mer DNA duplex (Hansen et al., 1998b); however, since the interproton distance is not necessarily known in advance, the interpretation of the angular dependence for the interproton interaction is more complicated than in the case of the ${ }^{1} \mathrm{H}^{-13} \mathrm{C}^{1}$ or ${ }^{1} \mathrm{H}^{-15} \mathrm{~N}$ vectors.

\section{RNA STRUCTURES}

To generate a family of structures consistent with the NMR data, structures are traditionally refined against the distance and torsion restraints along with geometric and nonbonded terms using restrained molecular dynamics calculations (Brünger and Karplus, 1991; Nilges, 1996). A number of RNA structures have been determined utilizing many of the heteronuclear techniques discussed in this review. Many of the problems in RNA NMR studies revolve around the difficulty of gathering a large data restraint set due to chemical shift overlap along with dynamics issues. These issues also need to be considered during the molecular modeling process and for interpreting the resulting family of structures. Furthermore, the paucity of protons along the backbone leaves few distance restraints to define the many degrees of freedom of the RNA backbone. Neither distance nor J-coupling-based NMR methods are available for the direct determination of the backbone angles $\alpha$ and $\zeta$. In general, traditionally applied restraints such as proton-proton distances or torsions accurately define local features of RNA structures, whereas global features like helical bending cannot be determined precisely using these restraint sets; however, parameters mentioned in the section above, such as residual dipolar couplings, hold the promise to provide global rather than local structural information for RNA structure determination. The data sets traditionally used as a restraint list in the structure determination include NOE and torsion restraints, and parameters such as cross-correlated relaxation rates and residual dipolar couplings have yet to be 
included in a published RNA structure determination.

\section{Overall Quality of RNA NMR Structures}

In evaluating the quality of a family of RNA NMR structures, a number of statistics can be evaluated: rmsd, number of NOE and torsion restraints, residual distance and torsion violations, and the largest distance and torsion violations. The distance restraints are further dissected into the number of interresidue, intraresidue, and intermolecular NOEs. A listing of RNA NMR structures is shown in Table 7.7.4 with the rmsd's shown in the context of the number of NOE and torsion restraints. The local rmsd is given because the overall global rmsd is usually in the 2.0 to $2.6 \AA$ ange, which might otherwise be indicative of poor convergence. This is because almost every RNA structure studied includes a region which is poorly defined, e.g., a disordered loop, terminal base pair, or a nucleotide without any internucleotide NOEs. This situation is comparable to protein NMR and X-ray studies, which often neglect the $\mathrm{N}$ - and $\mathrm{C}$-terminal ends of proteins because of the lack of structural data from these regions. Therefore, the more useful rmsd to consider includes only the region of interest and is usually a more accurate description of the quality of the structure than the overall global rmsd. However, for RNA NMR studies, the region that is defined as the structured "core" can be a subjective decision, as the tendency is to find a combination of nucleotides which will give the lowest possible rmsd. One alternative is to define the well-ordered region by using an average standard deviation matrix which will identify the ordered and disordered regions (Kundrot, 1996).

All the structures listed in Table 7.7.4 have low rmsd's, indicating that a family of structures converged to a very similar structure, but the crucial question is whether the structures are accurate. This question was addressed in great detail using synthetic sets of restraints as derived from the ribozyme crystal structure (Allain and Varani, 1997). As in all structural biology techniques, correlations with other biochemical and structural data are used to help determine the accuracy of the structure. For RNA NMR studies, it is possible to make mutations of the RNA to determine whether any specific nucleotide alters the structure or complex, as has been done in a few cases (Puglisi et al., 1995; Ye et al., 1995; Dieckmann et al., 1996) to help support the proposed interactions.
In addition, the GNRA tetraloops (where $\mathrm{N}$ is any nucleotide and $\mathrm{R}$ is a purine) were first determined by NMR (Heus and Pardi, 1991) and have now been seen in both the Hammerhead crystal and P4/P5/P6 IVS crystal structures (Pley et al., 1994a,b; Cate et al., 1996). The GNRA tetraloops determined by NMR and $\mathrm{X}$-ray crystallography are extremely similar and incorporate the same essential features. Furthermore, RNA NMR studies have been found to be very self-consistent, as all the general features and many of the specifics were very similar for the four structures that have been independently solved by two research groups.

\section{Choosing a Molecular Modeling Protocol}

The goal of the molecular modeling calculations is to start from a sufficiently random initial model and then explore as much conformational space as possible. It is difficult to assess whether the protocols currently used are sampling all conformational space consistent with the data; therefore, this is an area of much study (Brünger and Karplus, 1991). Three major types of initial models are predominantly used as shown in Table 7.7.4: random coordinates, random torsions, and distance geometry. The major difference between these approaches is the computational expense required to generate a family of structures. Generally, random torsions offer high convergence rates in the $40 \%$ to 50\% range (Aboul-ela et al., 1995; Allain and Varani, 1995; Allain et al., 1996; Jucker et al., 1996), while random coordinates require significant sorting of the atoms and generally generate lower convergence rates in the $10 \%$ to $20 \%$ range (Puglisi et al., 1995; Brodsky and Williamson, 1997). Distance geometry is an algorithm routinely used to sample conformational space in protein NMR studies with great success (de Vlieg and van Gunsteren, 1991). In RNA NMR studies, distance geometry has been found to be especially useful when many long-range, global fold type of NOEs are found as in peptide complexes and the highly folded ATP aptamer (Battiste et al., 1996; Dieckmann et al., 1996; Fan et al., 1996; Ye et al., 1996).

\section{Determining Bounds for Distance Restraints}

A large difference in the number of NOEs per nucleotide is seen in the structures summarized in Table 7.7.4, in part because not all NOEs are always included in the distance re-
Biophysical Analysis of Nucleic Acids

\subsubsection{1}

Supplement 2 


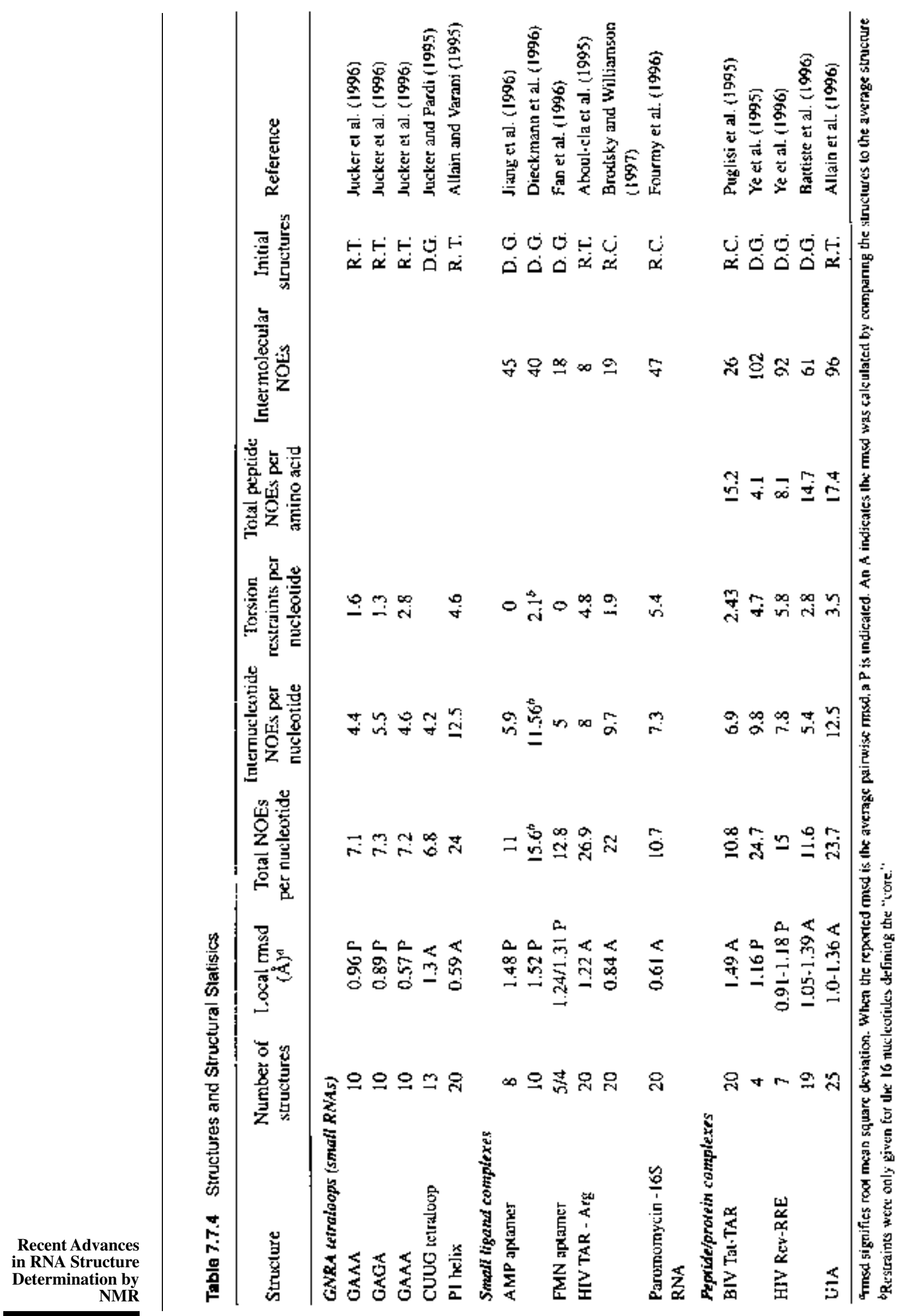


straint data set for molecular modeling calculations. These apparent discrepancies occur because, although some intranucleotide NOEs are important in defining RNA structure, there are a number of intraribose and intrabase NOEs that do not contain any useful information, either because the range of sugar puckers do not change these distances significantly within the precision that the restraints can be accurately defined, or because the covalent structure of the nucleotide itself defines the restraints. The HIV-2 TAR argininamide NMR study did not use intrabase H5-H6 and H5-H4 NOEs (Brodsky and Williamson, 1997). Also, one of the BIV Tat-TAR and one of the ATP aptamer studies excluded many "conformationally unimportant" NOEs from the NOE restraint list, thus accounting for the small difference between the total number of NOEs and internucleotide NOEs shown in Table 7.7.3 (Puglisi et al., 1995; Dieckmann et al., 1996).

Deciding what bounds to use for NOE restraints is a critical issue for RNA NMR structures. Modeling studies of protein structures using both synthetic and real data have demonstrated a correlation between the precision of a family of structures and the accuracy to a target structure (Liu et al., 1992). This correlation is critically dependent on the accuracy of the bounds used and the proper identification of NOEs; however, it is unclear whether this same correlation between rmsd and accuracy pertains to RNA structures which have fewer interresidue NOEs and lack the global fold, longrange NOEs often found in protein NMR studies. Unfortunately, the dynamic character of many RNA molecules on the NMR time scale prevents the accurate determination of tight bounds. For RNA NMR studies, NOE constraints are often determined semi-quantitatively and placed into four categories: strong, medium, weak, and very weak NOEs. Protein NMR studies have shown that with a sufficiently large restraint data set, a precise and accurate family of structures can be determined even when loose bounds are used (Liu et al., 1992). The RNA NMR studies listed in Table 7.7.4 have used different upper and lower bounds to define these categories. These differences lead to slightly different residual distance violation statistics, which may or may not reflect the quality of the structure. Each research group has used a slightly different methodology to determine the NOE bounds which also changes on a case-by-case basis depending on the quality of the spectra. The P1 helix, HIV TAR, and U1A studies set all the lower bounds to $1.8 \AA$ with upper bounds ranging from 3.0 $\AA$ for the most intense NOEs to $7.0 \AA$ for the weakest NOEs found in $\mathrm{H}_{2} \mathrm{O}$ experiments (Aboul-ela et al., 1995; Allain and Varani, 1995; Allain et al., 1996; Brodsky and Williamson, 1997). One of the reasons for this very conservative approach is demonstrated by the extreme case of the HIV TAR studies where a weakbinding ligand caused a variety of conformational exchange issues. This precluded the use of accurate tight bounds such that independent groups used very conservative bounds (Aboulela et al., 1995; Brodsky and Williamson, 1997); however, this approach may be too conservative in some cases, as much of the information in the NOE data is not being used. An alternative approach is to use slightly tighter bounds where the lower bounds are set to 1.8 , 2.5, and $3.5 \AA$, with upper bounds of $2.5,3.5$, and $5 \AA$ for the strong, medium, and weak categories, respectively (Puglisi et al., 1995; Ye et al., 1995, 1996; Fan et al., 1996; Fourmy et al., 1996; Jucker et al., 1996). This strategy has been used in a number of cases with water NOESY spectra treated differently to account for possible spin diffusion effects of close amino protons. Both these approaches lead to a family of converged structures as shown in Table 7.7.4; however, when looser bounds were used, a significant number of restraints were used and thus presumably overcame the larger conformational space allowed by each bound as illustrated by the P1 helix, U1A, and HIV TAR studies (Aboul-ela et al., 1995; Allain and Varani, 1995; Allain et al., 1996; Brodsky and Williamson, 1997). The danger of using tight bounds is that errors can be made, some of which may lead to the wrong structure or can limit the rate of convergence, making the structure calculations difficult. Some techniques have been developed to help limit the amount of spin diffusion and therefore increase the accuracy of tight bounds by limiting the effects of spin diffusion, thus increasing the precision and presumably the accuracy of the resulting structures (Hoogstraten and Pardi, 1998a).

\section{PROSPECTS FOR LARGE RNA MOLECULES}

Most NMR studies have focused on small hairpin elements ( 20 to 40 nucleotides) that contain unusual base-pairing elements and/or are the recognition sites for proteins or small molecules. Expanding the size of RNA molecules that can be studied by NMR to the 70 to 80 nucleotide range would greatly enhance the ability to study biologically significant RNAs.
Biophysical Analysis of Nucleic Acids

\subsubsection{3}

Supplement 2 
The two significant technical problems that must be overcome in order to study large macromolecules are the chemical shift overlap in spectra from the increased number of resonances and the increased transverse relaxation times that significantly reduce the sensitivity of multidimensional heteronuclear experiments. The first problem can be most easily overcome by the selective segmental and/or type-specific ${ }^{13} \mathrm{C} /{ }^{15} \mathrm{~N}$-labeling strategies outlined earlier, though strategies that allow more flexibility in the labeling patterns will probably be necessary. The relaxation problem is more fundamental and is difficult to overcome, but promising strategies have recently been developed.

\section{Utilizing TROSY in RNA Assignments and Structure Determinations}

A new class of NMR experiments based on transverse relaxation-optimized spectroscopy (TROSY) promises a several-fold increase of the molecular size of RNA structures accessible (Pervushin et al., 1997; Wüthrich, 1998). Different relaxation mechanisms usually contribute to the rapid decay of magnetization during NMR experiments. The TROSY approach uses interference effects between different relaxation mechanisms in a constructive manner, resulting in partial cancellation of transverse relaxation effects, thus dramatically increasing the sensitivity of NMR. The efficiency of this mutual cancellation is a function of the spin pairs studied, the molecular weight, and the external magnetic field available. For example, for a ${ }^{1} \mathrm{H}^{15} \mathrm{~N}$ spin pair in a molecule with a molecular weight of $150 \mathrm{kDa}$, nearly complete cancellation of magnetization decay can be achieved with a $900 \mathrm{MHz}$ (proton resonance frequency) spectrometer, which will soon become available. Basically all NMR experiments that excite and detect imino proton resonances in RNA potentially benefit from the TROSY approach, which was originally proposed for ${ }^{1} \mathrm{H}-{ }^{15} \mathrm{~N}$ amide moieties in proteins. Furthermore, recent experiments show significant gains in sensitivity for ${ }^{1} \mathrm{H}-{ }^{13} \mathrm{C}$ moieties in aromatic spin systems (Brutscher et al., 1998; Pervushin et al., 1998b; Meissner and Sorensen, 1999a). These applications have an even greater impact on the experiments commonly used for the investigation of RNA by NMR, because $\mathrm{HCCH}$-type experiments for the assignment of the ribose resonances or HSQCtype experiments for either ribose or base ${ }^{1} \mathrm{H}$ ${ }^{13} \mathrm{C}$ spin pairs potentially benefit, opening the field for NMR studies on larger RNA systems in the future. Finally, most recent studies indi- cate sensitivity gains for the collection of $\mathrm{NOE}$ data, essential for a structure determination in NOESY experiments (Meissner and Sorensen, 1999b, 2000; Pervushin et al., 1999).

\section{Sensitivity Enhancement Through Multiple Quantum Line Narrowing}

Two approaches can be applied to obtain one-bond ${ }^{1} \mathrm{H}^{-13} \mathrm{C}$ correlations, HSQC or HMQC experiments. Recent studies show that the multiple quantum (MQ) experiments are more sensitive for correlating carbon and proton nuclei in RNA (Marino et al., 1997). The reason for this is similar to considerations given in the previous section. The main sources of relaxation for $\mathrm{CH}$ and $\mathrm{CH}_{2}$ moieties are not effective during multiple quantum evolution times; thus, MQ lifetimes are increased with respect to SQ (single quantum) coherences, present in HSQC experiments. The enhancement was demonstrated to be about a factor of 3 for a 36-mer RNA hairpin (Marino et al., 1997). This encouraging result has implications for through-bond assignment experiments, mentioned in earlier sections. Optimized HCN pulse schemes for the through-bond correlation of ribose and base resonances utilizing MQ instead of SQ evolution periods have been proposed and show significant sensitivity gains, essential for successful investigations of larger RNA systems (Fiala et al., 1998; Sklenar et al., 1998).

In addition, specific deuteration of ribose or base resonances is likely to be beneficial. Full sensitivity can be retained at a particular position while still mitigating relaxation effects. New labeling patterns that incorporate both ${ }^{13} \mathrm{C}$ and ${ }^{2} \mathrm{H}$ will probably be needed, so that multidimensional experiments can be performed to resolve overlap problems. In addition, ${ }^{13} \mathrm{C}$ labels in the ribose ring, along with deuteration of all the protons except at the $\mathrm{H} 1^{\prime}$ position, has the potential to improve the feasibility of HCP sequential assignment experiments for larger RNA through increased efficiency of ${ }^{13} \mathrm{C}$ TOCSY transfer (Dayie et al., 1998).

To achieve a level of precision equivalent to that which has been commonly found in protein NMR of medium-sized $(<20-\mathrm{kD})$ proteins, relatively more data is expected to be required and used in the structure determination process (Liu et al., 1992). Given the difficulties in acquiring any data for larger systems, this presents a particularly difficult situation. In RNA NMR, where good precision for even mediumsized ( $<40$ nucleotide) RNAs is a difficult and tedious task, the challenge may be even greater. 
However, the new methods described above, especially dipolar couplings, hold the promise of great impact on the structure determination of even larger RNA systems. Perhaps dependence on other biochemical and biophysical techniques like transient electric birefringence and fluorescence resonance energy transfer measurements to gain additional structural restraints to aid in the structure determination process will become useful and necessary to solve large RNA structures.

\section{LITERATURE CITED}

Aboul-ela, F., Karn, J., and Varani, G. 1995. The structure of the human immunodeficiency virus Type-1 TAR RNA reveals principles of RNA recognition by Tat protein. J. Mol. Biol. 253:313332.

Allain, F.H.-T. and Varani, G. 1995. Structure of the P1 helix from group I self-splicing introns. $J$. Mol. Biol. 250:333-353.

Allain, F.H.-T. and Varani, G. 1997. How accurately and precisely can RNA structure be determined by NMR. J. Mol. Biol. 267:338-351.

Allain, F.H.-T., Gubser, C.C., Howe, P.W.A., Nagai, K., Neuhaus, D., and Varani, G. 1996. Specificity of ribonucleoprotein interaction determined by RNA folding during complex formation. Nature 380:646-650.

Batey, R.T., Inada, M., Kujawinski, E., Puglisi, J.D., and Williamson, J.R. 1992. Preparation of isotopically labeled ribonucleotides for multidimensional NMR spectroscopy of RNA. Nucl. Acids Res. 20:4515-4523.

Batey, R.T., Battiste, J.L., and Williamson, J.R. 1995. Preparation of isotopically enriched RNAs for heteronuclear NMR. Methods Enzymol. 261: 300-322.

Battiste, J.L., Tan, R., Frankel, A.D., and Williamson, J.R. 1995. Assignment and modeling of the Rev Response Element RNA bound to a Rev peptide using ${ }^{13} \mathrm{C}$-heteronuclear NMR. J. Biomol. NMR 6:375-389.

Battiste, J.L., Mao, H., Rao, N.S., Tan, R., Muhandiram, D.R., Kay, L.E., Frankel, A.D., and Williamson, J.R. 1996. $\alpha$-helix-RNA major groove recognition in an HIV-1 Rev peptide-RRE RNA complex. Science 273:1547-1551.

Brodsky, A.S. and Williamson, J.R. 1997. Solution structure of the HIV-2 TAR-argininamide complex. J. Mol. Biol. 267:624-39.

Brünger, A.T. and Karplus, M. 1991. Molecular dynamics simulations with experimental restraints. Acc. Chem. Res. 24:54-61.

Brutscher, B., Boisbouvier, J., Pardi, A., Marion, D., and Simorre, J.-P. 1998. Improved sensitivity and resolution in ${ }^{1} \mathrm{H}-{ }^{13} \mathrm{C}$ NMR experiments of RNA. J. Am. Chem. Soc. 120:11845-11851.
Cai, Z. and Tinoco, I. 1996. Solution structure of loop A from the hairpin ribozyme from tobacco ringspot virus satellite. Biochemistry 35:60266036.

Cate, J.H., Gooding, A.R., Podell, E., Zhou, K., Golden, B.L., Kondrot, C.E., Cech, T.R., and Doudna, J.A. 1996. Crystal structure of a group I ribozyme domain: Principles of RNA packing. Science 273:1678-1685.

Cilley, C.D. and Williamson, J.R. 1997. Analysis of bacteriophage $\mathrm{N}$ protein and peptide binding to boxB RNA using polyacrylamide gel coelectrophoresis (PACE). RNA 3:57-67.

Clore, G.M., Murphy, E.C., Gronenborn, A.M., and Bax, A. 1998. Determination of three-bond ${ }^{1} \mathrm{H}^{\prime}$ ${ }^{31} \mathrm{P}$ couplings in nucleic acids and protein-nucleic acid complexes by quantitative $\mathrm{J}$ correlation spectroscopy. J. Magn. Reson. 134:164-7.

Dayie, K.T., Tolbert, T.J., and Williamson, J.R. 1998. 3D C(CC)H TOCSY experiment for assigning protons and carbons in uniformly ${ }^{13} \mathrm{C}$ and selectively ${ }^{2} \mathrm{H}$-labeled RNA. J. Magn. Reson. 130:97-101.

de Vlieg, J. and van Gunsteren, W.F. 1991. Combined procedures of distance geometry and molecular dynamics for determining protein structure from nuclear magnetic resonance data. Methods Enzymol. 202:268-300.

Dieckmann, T. and Feigon, J. 1994. Heteronuclear techniques in NMR studies of RNA and DNA. Curr. Opin. Struct. Biol. 4:745-749.

Dieckmann, T., Suzuki, E., Nakamura, G.D., and Feigon, J. 1996. Solution structure of an ATPbinding RNA aptamer reveals a novel fold. $R N A$ 2:628-640.

Dingley, A.J. and Grzesiek, S. 1998. Direct observation of hydrogen bonds in nucleic acid base pairs by internucleotide ${ }^{2} \mathrm{~J}_{\mathrm{NN}}$ couplings. J. Am. Chem. Soc. 120:8293-8297.

Fan, P., Suri, A.K., Fiala, R., Live, D., and Patel, D.J. 1996. Molecular recognition in the FMN-RNA aptamer complex. J. Mol. Biol. 258:480-500.

Farmer, B.T., Muller, L., Nikonowicz, E.P., and Pardi, A. 1993. Unambiguous resonance assignments in ${ }^{13} \mathrm{C}$, ${ }^{15} \mathrm{~N}$-labeled nucleic acids by $3 \mathrm{D}$ triple-resonance NMR. J. Am. Chem. Soc. 115:11040-11041.

Farmer, B.T., Mueller, L., Nikonowicz, E.P., and Pardi, A. 1994. Unambiguous through-bond sugar-to-base correlations for purines in ${ }^{13} \mathrm{C},{ }^{15} \mathrm{~N}$-labeled nucleic acids: The $\mathrm{H}_{\mathrm{s}} \mathrm{C}_{\mathrm{s}} \mathrm{N}_{\mathrm{b}}$, $\mathrm{H}_{\mathrm{s}} \mathrm{C}_{\mathrm{s}}(\mathrm{N})_{\mathrm{b}} \mathrm{C}_{\mathrm{b}}$, and $\mathrm{H}_{\mathrm{b}} \mathrm{N}_{\mathrm{b}} \mathrm{C}_{\mathrm{b}}$ experiments. J. Biomol. NMR 4:129-133.

Felli, I.C., Richter, C., Griesinger, C., and Schwalbe, H. 1999. Determination of RNA sugar pucker mode from cross-correlated relaxation in solution NMR. J. Am. Chem. Soc. 121:1956-1957.

Fesik, S., Eaton, H., Olejniczak, E., and Zuiderweg, E. 1990. 2D and 3D NMR spectroscopy employing ${ }^{13} \mathrm{C}-{ }^{13} \mathrm{C}$ magnetization transfer by isotropic mixing. Spin identification in large proteins. $J$. Am. Chem. Soc. 112:886-888.
Biophysical Analysis of Nucleic Acids 
Fiala, R., Jiang, F., and Patel, D.J. 1996. Direct correlation of exchangeable and nonexchageable protons on purine bases in ${ }^{13} \mathrm{C},{ }^{15} \mathrm{~N}$-labeled RNA using a HCCNH-TOCSY experiment. J. Am. Chem. Soc. 118:689-690.

Fiala, R., Jiang, F., and Sklenar, V. 1998. Sensitivity optimized $\mathrm{HCN}$ and $\mathrm{HCNCH}$ experiments for ${ }^{13} \mathrm{C} /{ }^{15} \mathrm{~N}$-labeled oligonucleotides. J. Biomol. NMR 12:373-383.

Foldesi, A., Nilsson, F.P.R., Glemarec, C., Gioeli, C., and Chattopadhyaya, J. 1992. Synthesis of 1'\#, 2', 3', 4'\#, 5', 5"'-2H6-beta-D-ribonucleosides and 1'\#, 2', 3', 4'\#, 5', 5''-2H7-beta-D$2^{\prime}$-deoxyribonucleosides for selective suppression of proton resonances in partially deuterated oligo-DNA, oligo-RNA and in $2,4 \mathrm{~A}$ core $(1 \mathrm{H}-$ NMR window). Tetrahedron 48:9033-9072.

Foldesi, A., Yamakage, S.-I., Nilsson, F.P.R., Maltseva, T.V., and Chattopadhyaya, J. 1996. The use of non-uniform deuterium labelling ["NMRwindow"] to study the NMR structure of a 21 mer RNA hairpin. Nucl. Acids Res. 24:1187-1194.

Fourmy, D., Recht, M.I., Blanchard, S.C., and Puglisi, J.D. 1996. Structure of the A site of Escherichia coli $16 \mathrm{~S}$ ribosomal RNA complexed with an aminoglycoside antibiotic. Science 274:1367-1371.

Giessner-Prettre, C. and Pullman, B. 1987. Quantum mechanical calculations of NMR chemical shifts in nucleic acids. Q. Rev. Biophys. 20:113172.

Glaser, S.J., Schwalbe, H., Marino, J.P., and Griesinger, C. 1996. Directed TOCSY, a method for selection of directed correlations by optimal combinations of isotropic and longitudinal mixing. J. Magn. Reson. B112:160-180.

Glemarec, C., Kukel, J., Foldesi, A., Maltseva, T., Sandstrom, A., Kirsebom, L.A., and Chattopadhyaya, J. 1996. The NMR structure of 31mer RNA domain of Escherichia coli RNase P RNA using its non-uniformly deuterium labelled counterpart [the "NMR-window" concept]. Nucl. Acids Res. 24:2022-2035.

Gorenstein, D.G. and Luxon, B.A. 1979. High-resolution phosphorus nuclear magnetic resonance spectra of yeast phenylalanine transfer ribonucleic acid. melting curves and relaxation effects. Biochemistry 18:3796-3804.

Gueron, M. and Leroy, J.L. 1995. Studies of base pair kinetics by NMR measurement of proton exchange. Methods Enzymol. 261:383-413.

Gueron, M. and Shulman, R.G. $1975 .{ }^{31} \mathrm{P}$ magnetic resonance of tRNA. Proc. Natl. Acad. Sci. U.S.A. 72:3482-3485.

Hansen, M.R., Mueller, L., and Pardi, A. 1998a. Tunable alignment of macromolecules by filamentous phage yields dipolar coupling interactions. Nature Struct. Biol. 5:1065-1074.

Recent Advances in RNA Structure Determination by NMR

Hansen, M.R., Rance, M., and Pardi, A. 1998b. Observation of long-range ${ }^{1} \mathrm{H}-{ }^{1} \mathrm{H}$ distances in solution by dipolar coupling interactions. J. Am. Chem. Soc. 120:11210-11211.
Hennig, M. and Williamson, J.R. 2000. Detection of $\mathrm{N}-\mathrm{H}$...N hydrogen bonding in RNA via scalar coupling in the absence of observable imino proton resonances. Nucl. Acids Res. 28:15851593.

Heus, H. and Pardi, A. 1991. Structural features that give rise to unusual stability of RNA hairpins containing GNRA loops. Science 253:191-194.

Heus, H.A., Wijmenga, S.S., van de Ven, F.J.M., and Hilbers, C.W. 1994. Sequential backbone assignment in ${ }^{13} \mathrm{C}$-labeled RNA via through-bond coherence transfer using three-dimensional triple resonance spectroscopy $\left({ }^{1} \mathrm{H},{ }^{13} \mathrm{C},{ }^{31} \mathrm{P}\right)$ and twodimensional hetero TOCSY. J. Am. Chem. Soc. 116:4983-4984.

Hines, J.V., Varani, G., Landry, S.M., and Tinoco, J.I. 1993. The stereospecific assignment of $\mathrm{H}^{\prime}$ and $\mathrm{H}^{\prime \prime}$ in RNA using the sign of two-bond carbon-proton scalar coupling. J. Am. Chem. Soc. 115:11002-11003.

Hines, J.V., Landry, S.M., Varani, G., and Tinoco, J.I. 1994. Carbon-proton scalar couplings in RNA: 3D heteronuclear and 2D isotope-edited NMR of a ${ }^{13} \mathrm{C}$-labeled extra-stable hairpin. $J$. Am. Chem. Soc. 116:5823-5831.

Hoogstraten, C.G. and Pardi, A. 1998a. Improved distance analysis in RNA using network-editing techniques for overcoming errors due to spin diffusion. J. Biomol. NMR 11:85-95.

Hoogstraten, C.G. and Pardi, A. 1998b. Measurement of carbon-phosphorus $\mathrm{J}$ coupling constants in RNA using spin-echo difference constanttime HCCH-COSY. J. Magn. Reson. 133:236240.

Hu, W., Kakalis, L.T., Jiang, L., Jiang, F., Ye, X., and Majumdar, A. 1998. 3D HCCH-COSY-TOCSY experiment for the assignment of ribose and amino acid side chains in ${ }^{13} \mathrm{C}$ labeled RNA and protein. J. Biomol. NMR 12:559-564.

Jiang, F., Kumar, R.A., Jones, R.A., and Patel, D.J. 1996. Structural basis of RNA folding and recognition in an AMP-RNA aptamer complex. $\mathrm{Na}$ ture 382:183-186.

Jucker, F.M. and Pardi, A. 1995. Solution structure of the CUUG hairpin loop: A novel RNA tetraloop motif. Biochemistry 34:14416-27.

Jucker, F.M., Heus, H.A., Yip, P.F., Moors, E.H.M., and Pardi, A. 1996. A network of heterogeneous hydrogen bonds in GNRA tetraloops. J. Mol. Biol. 264:968-980.

Karplus, M. 1959. Contact electron-spin coupling of nuclear magnetic moments. J. Chem. Phys. 30:11-15.

Kay, L.E., Ikura, M., and Bax, A. 1990. Proton-proton correlation via carbon-carbon couplings: A three-dimensional NMR approach for the assignment of aliphatic resonances in proteins labeled with carbon-13. J. Am. Chem. Soc. 112:888-889.

Kellogg, G.W. 1992. Proton-detected heteroTOCSY experiments with application to nucleic acids. J. Magn. Reson. 98:176-182. 
Kellogg, G.W. and Schweitzer, B.I. 1993. Two- and three-dimensional ${ }^{31} \mathrm{P}$-driven NMR procedures for complete assignment of backbone resonances in oligodeoxyribonucleotides. J. Biomol. NMR 3:577-95.

Krishnan, V.V. and Rance, M. 1995. Influence of chemical exchange among homonuclear spins in heteronuclear coherence-transfer experiments in liquids. J. Magn. Reson. A A116:97-106.

Kundrot, C. 1996. Rapid identification of ordered and disordered domains in NMR structures. $J$. Am. Chem. Soc. 118:8725-8726.

Legault, P., Farmer, B.T., II, Mueller, L., and Pardi, A. 1994. Through-bond correlation of adenine protons in a ${ }^{13} \mathrm{C}$-labeled ribozyme. J. Am. Chem. Soc. 116:2203-2204.

Legault, P., Jucker, F.M., and Pardi, A. 1995. Improved measurement of ${ }^{13} \mathrm{C},{ }^{31} \mathrm{P} \mathrm{J}$ coupling constants in isotopically labeled RNA. FEBS Lett. 362:156-160.

Liu, Y., Zhao, D., Altman, R., and Jardetzky, O. 1992. A systematic comparison of three structure determination methods from NMR data: Dependence upon quality and quantity of data. $J$. Biomol. NMR 2:373-388.

Mao, H. and Williamson, J.R. 1999. Assignment of the L30-mRNA complex using selective isotopic labeling and RNA mutants. Nucl. Acids Res. 27:4059-4070.

Mao, H., White, S.A., and Williamson, J.R. 1999. A novel loop-loop recognition motif in the yeast ribosomal protein L30 autoregulatory RNA complex [see comments]. Nature Struct. Biol. 6:1139-1147.

Marino, J.P., Prestegard, J.H., and Crothers, D.M. 1994a. Correlation of adenine $\mathrm{H} 2 / \mathrm{H} 8$ resonances in uniformly ${ }^{13} \mathrm{C}$ labeled RNAs by $2 \mathrm{D} \mathrm{HCCH}-$ TOCSY: A new tool for ${ }^{1} \mathrm{H}$ assignment. J. Am. Chem. Soc. 116:2205-2206.

Marino, J.P., Schwalbe, H., Anklin, C., Bermel, W., Crothers, D.M., and Griesinger, C. 1994b. A three-dimensional triple-resonance ${ }^{1} \mathrm{H},{ }^{13} \mathrm{C},{ }^{31} \mathrm{P}$ experiment: Sequential through-bond correlation of ribose protons and intervening phosphorous along the RNA oligonucleotide backbone. J. Am. Chem. Soc. 116:6472-6473.

Marino, J.P., Schwalbe, H., Anklin, C., Bermel, W., Crothers, D.M., and Griesinger, C. 1995. Sequential correlation of anomeric ribose protons and intervening phosphorus in RNA oligonucleotides by a ${ }^{9} \mathrm{H},{ }^{13} \mathrm{C},{ }^{31} \mathrm{P}$ triple resonance experiment: HCP-CCH-TOCSY. J. Biomol. NMR 5:87-92.

Marino, J.P., Diener, J.L., Moore, P.B., and Griesinger, C. 1997. Multiple-quantum coherence dramatically enhance the sensitivity of $\mathrm{CH}$ and $\mathrm{CH} 2$ correlations in uniformly ${ }^{13} \mathrm{C}$-labeled RNA. $J$. Am. Chem. Soc. 119:7361-7366.

Marino, J.P., Schwalbe, H., and Griesinger, C. 1999. J-coupling restraints in RNA structure determination. Acc. Chem. Res. 32:614-623.
Meissner, A. and Sorensen, O.W. 1999a. Optimization of three-dimensional TROSY-type $\mathrm{HCCH}$ NMR correlation of aromatic ${ }^{1} \mathrm{H}_{-}{ }^{13} \mathrm{C}$ groups in proteins. J. Magn. Reson. 139:447-450.

Meissner, A. and Sorensen, O.W. 1999b. Suppression of diagonal peaks in TROSY-type ${ }^{1} \mathrm{H}$ NMR NOESY spectra of ${ }^{15} \mathrm{~N}$-labeled proteins. $J$. Magn. Reson. 140:499-503.

Meissner, A. and Sorensen, O.W. 2000. Three-dimensional protein NMR TROSY-type (15)N-resolved (1)H(N)-(1)H(N) NOESY spectra with diagonal peak suppression. J. Magn. Reson. 142:195-198.

Mohebbi, A. and Shaka, A.J. 1991. Improvements in carbon-13 broadband homonuclear cross-polarization for 2D and 3D NMR. Chem. Phys. Lett. 178:374-378.

Mueller, L., Legault, P., and Pardi, A. 1995. Improved RNA structure determination by detection of NOE contacts to exchange-broadened amino protons. J. Am. Chem. Soc. 117:1104311048.

Nikonowicz, E.P. and Pardi, A. 1992. Three-dimensional heteronuclear NMR studies of RNA. $\mathrm{Na}$ ture 355:184-186.

Nikonowicz, E.P. and Pardi, A. 1993. An efficient procedure for assignment of the proton, carbon and nitrogen resonances in ${ }^{13} \mathrm{C} /{ }^{15} \mathrm{~N}$ labeled nucleic acids. J. Mol. Biol. 232:1141-1156.

Nikonowicz, E.P., Sirr, A., Legault, P., Jucker, F.M., Baer, L.M., and Pardi, A. 1992. Preparation of ${ }^{13} \mathrm{C}$ and ${ }^{15} \mathrm{~N}$ labelled RNAs for heteronuclear multi-dimensional NMR studies. Nucl. Acids Res. 20:4507-4513.

Nilges, M. 1996. Structure calculation from NMR data. Curr. Opin. Struct. Biol. 6:617-623.

Otting, G. and Wüthrich, K. 1989a. Extended heteronuclear editing of 2D 1H NMR spectra of isotope-labeled proteins, using the $X(\omega 1, \omega 2)$ double half filter. J. Magn. Reson. 85:586-594.

Otting, G. and Wüthrich, K. 1989b. Studies of protein hydration in aqueous solution by direct NMR observation of individual protein-bound water molecules. J. Am. Chem. Soc. 111:18711875.

Otting, G. and Wüthrich, K. 1990. Heteronuclear filters in two-dimensional $[1 \mathrm{H}, 1 \mathrm{H}]-\mathrm{NMR}$ spectroscopy: Combined use with isotope labelling for studies of macromolecular conformation and intermolecular interactions. Q. Rev. Biophys. 23:39-96.

Otting, G., Liepinsh, E., and Wüthrich, K. 1991. Protein hydration in aqueous solution. Science 254:974-980.

Pardi, A. 1995. Multidimensional heteronuclear NMR experiments for structure determination of isotopically labeled RNA. Methods Enzymol. 261:350-380.

Pardi, A. and Nikonowicz, E.P. 1992. Simple procedure for resonance assignment of the sugar protons in ${ }^{13}$ C-labeled RNAs. J. Am. Chem. Soc. 114:9202-9203.
Biophysical Analysis of Nucleic Acids 
Pervushin, K., Riek, R., Wider, G., and Wüthrich, K. 1997. Attenuated T2 relaxation by mutual cancellation of dipole-dipole coupling and chemical shift anisotropy indicates an avenue to NMR structures of very large biological macromolecules in solution. Proc. Natl. Acad. Sci. U.S.A. 94:12366-71.

Pervushin, K., Ono, A., Fernandez, C., Szyperski, T., Kainosho, M., and Wüthrich, K. 1998a. NMR scalar couplings across Watson-Crick base pair hydrogen bonds in DNA observed by transverse relaxation-optimized spectroscopy. Proc. Natl. Acad. Sci. U.S.A. 95:14147-14151.

Pervushin, K., Riek, R., Wider, G., and Wüthrich, K. 1998b. Transverse relaxation-optimized spectroscopy (TROSY) for NMR studies of aromatic spin systems in ${ }^{13} \mathrm{C}$-labeled proteins. J. Am. Chem. Soc. 120:6394-6400.

Pervushin, K., Wider, G., Riek, R., and Wüthrich, K. 1999. The 3D NOESY-[1H,15N,1H]-ZQTROSY NMR experiment with diagonal peak suppression. Proc. Natl. Acad. Sci. U.S.A. 96:9607-9612.

Pley, H., Flaherty, K.M., and McKay, D.B. 1994a. Three-dimensional structure of a hammerhead ribozyme. Nature 372:68-74.

Pley, H.W., Flaherty, K.M., and McKay, D.B. 1994b. Model of an RNA tertiary interaction from the structure of an intermolecular complex between a GAAA tetraloop and an RNA helix. Nature 372:111-113.

Prestegard, J.H. 1998. New techniques in structural NMR-Anisotropic interactions. Nature Struct. Biol. 5:517-522.

Puglisi, J.D., Chen, L., Blanchard, S., and Frankel, A.D. 1995. Solution structure of a bovine immunodeficiency virus tat TAR RNA-peptide complex. Science 270:1200-1203.

Quant, S., Wechselberger, R.W., Wolter, M.A., Wörner, K.-H., Schell, P., Engels, J.W., Griesinger, C., and Schwalbe, H. 1994. Chemical synthesis of ${ }^{13} \mathrm{C}$-labelled monomers for the solidphase and template controlled enzymatic synthesis of DNA and RNA oligomers. Tetrahedron Lett. 35:6649-6652.

Reif, B., Hennig, M., and Griesinger, C. 1997. Direct measurement of angles between bond vectors in high-resolution NMR. Science 276:12301233.

Richter, C., Reif, B., Wörner, K.-H., Quant, S., Marino, J.P., Engels, J.W., Griesinger, C., and Schwalbe, H. 1998. A new experiment for the measurement of ${ }^{n} \mathrm{~J}(\mathrm{C}, \mathrm{P})$ coupling constants including ${ }^{3} \mathrm{~J}\left(\mathrm{C} 4^{\prime}{ }_{\mathrm{i}}, \mathrm{P}_{\mathrm{i}}\right)$ and ${ }^{3} \mathrm{~J}\left(\mathrm{C}^{\prime}{ }^{\prime}{ }_{\mathrm{i}}, \mathrm{P}_{\mathrm{i}+1}\right)$ in oligonucleotides. J. Biomol. NMR 12:223-230.

Richter, C., Griesinger, C., Felli, I.C., Cole, P.T., Varani, G., and Schwalbe, H. 1999. Determination of sugar conformation in large RNA oligonucleotides from analysis of dipole-dipole cross-correlated relaxation by solution NMR spectroscopy. J. Biomol. NMR 15:241-250.
Salemink, P.J.M., Swarthof, T., and Hilbers, C.W. 1979. Studies of yeast phenylalanine-accepting transfer ribonucleic acid backbone structure in solution by phosphorous-31 nuclear magnetic resonance spectroscopy. Biochemistry 18:34773485 .

SantaLucia, J., Shen, L.X., Cai, Z., Lewis, H., and Tinoco, I. 1995. Synthesis and NMR of RNA with selective isotopic enrichment in the bases. Nucl. Acids Res. 23:4913-4921.

Schwalbe, H., Samstag, W., Engels, J.W., Bermel, W., and Griesinger, C. 1993. Determination of $3 \mathrm{~J}(\mathrm{C}, \mathrm{P})$ and $3 \mathrm{~J}(\mathrm{H}, \mathrm{P})$ coupling constants in nucleotide oligomers with FIDS-HSQC. J. Biomol. NMR 3:479-486.

Schwalbe, H., Marino, J.P., King, G.C., Wechselberger, R., Bermel, W., and Griesinger, C. 1994. Determination of a complete set of coupling constants in ${ }^{13} \mathrm{C}$-labeled oligonucleotides. $J$. Biomol. NMR 4:631-644.

Schwalbe, H., Marino, J.P., Glaser, S.J., and Griesinger, C. 1995. Measurement of H,H-coupling constants associated with $v 1, v 2$, and $v 3$ in uniformly 13C labeled RNA by HCC-TOCSYCCH-E. COSY. J. Am. Chem. Soc. 117:72517252.

Scott, W.G., Finch, J.T., and Klug, A. 1995. The crystal structure of an all-RNA hammerhead ribozyme: A proposed mechanism for RNA catalytic cleavage. Cell 81:991-1002.

Simorre, J.-P., Zimmermann, G.R., Pardi, A., Farmer, B.T., II, and Mueller, L. 1995. Triple resonance $\mathrm{HNCCCH}$ experiments for correlating exchangeable and nonexchangeable cytidine and uridine base protons in RNA. J. Biomol. NMR 6:427-432.

Simorre, J.P., Zimmermann, G.R., Mueller, L., and Pardi, A. 1996a. Correlation of the guanosine exchangeable and nonexchangeable base protons in ${ }^{13} \mathrm{C}-/^{15} \mathrm{~N}$-labeled RNA with an HNCTOCSY-CH experiment. J. Biomol. NMR 7:153156.

Simorre, J.-P., Zimmermann, G., Mueller, L., and Pardi, A. 1996b. Triple-resonance experiments for assignment of adenine base resonances in ${ }^{13} \mathrm{C} /{ }^{15} \mathrm{~N}$-labeled RNA. J. Am. Chem. Soc. 118:5316-5317.

Sklenar, V. and Bax, A. 1987. Spin echo water suppression for the generation of pure phase two-dimensional NMR spectra. J. Magn. Reson. 74:469-479.

Sklenar, V., Miyashiro, H., Zon, G., Miles, H.T., and Bax, A. 1986. Assignment of the ${ }^{31} \mathrm{P}$ and ${ }^{1} \mathrm{H}$ resonances in oligonucleotides by two-dimensional NMR spectroscopy. FEBS Lett. 208:9498.

Sklenar, V., Brooks, B.R., Zon, G., and Bax, A. 1987. Absorption mode two-dimensional NOE spectroscopy of exchangeable protons in oligonucleotides. FEBS Lett. 216:249-252.
Recent Advances in RNA Structure Determination by NMR 
Sklenar, V., Peterson, R.D., Rejante, M.R., and Feigon, J. 1993a. Two- and three-dimensional HCN experiments for correlating base and sugar resonances in ${ }^{15} \mathrm{~N},{ }^{13} \mathrm{C}$-labeled RNA oligonucleotides. J. Biomol. NMR 3:721-7.

Sklenar, V., Peterson, R.D., Rejante, M.R., Wang, E., and Feigon, J. 1993b. Two-dimensional tripleresonance $\mathrm{HCNCH}$ experiment for direct correlation of ribose $\mathrm{H}^{\prime}$ and base $\mathrm{H} 8, \mathrm{H} 6$ protons in ${ }^{13} \mathrm{C},{ }^{15} \mathrm{~N}$-labeled RNA oligonucleotides. J. Am. Chem. Soc. 115:12181-12182.

Sklenar, V., Peterson, R.D., Rejante, M.R., and Feigon, J. 1994. Correlation of nucleotide base and sugar protons in a ${ }^{15} \mathrm{~N}$-labeled HIV-1 RNA oligonucleotide by ${ }^{1} \mathrm{H}_{-}{ }^{15} \mathrm{~N}$ HSQC experiments. J. Biomol. NMR 4:117-22.

Sklenar, V., Dieckmann, T., Butcher, S.E., and Feigon, J. 1996. Through-bond correlation of imino and aromatic resonances in ${ }^{13} \mathrm{C},{ }^{15} \mathrm{~N}$-labeled RNA via heteronuclear TOCSY. J. Biomol. NMR 7:83-87.

Sklenar, V., Dieckmann, T., Butcher, S.E., and Feigon, J. 1998. Optimization of triple-resonance $\mathrm{HCN}$ experiments for application to larger RNA oligonucleotides. J. Magn. Reson. 130:119-124.

Szyperski, T., Fernandez, C., Ono, A., Wüthrich, K., and Kainosho, M. 1999. The 2D [ $\left.{ }^{31} \mathrm{P}\right]$ spin-echodifference constant-time $\left[{ }^{13} \mathrm{C},{ }^{\mathrm{I}} \mathrm{H}\right]$-HMQC experiment for simultaneous determination of $3 \mathrm{~J}\left(\mathrm{H}^{\prime} \mathrm{P}\right)$ and $3 \mathrm{~J}\left(\mathrm{C} 4^{\prime} \mathrm{P}\right)$ in ${ }^{13} \mathrm{C}$-labeled nucleic acids and their protein complexes. J. Magn. Reson. 140:491-494.

Tjandra, N. and Bax, A. 1997a. Direct measurement of distances and angles in biomolecules by NMR in a dilute liquid crystalline medium [see comments]. Science 278(5340):1111-1114. [published erratum appears in Science 1997, 278(5344):1697]

Tjandra, N. and Bax, A. 1997b. Measurement of dipolar contributions to $1 \mathrm{JCH}$ splittings from magnetic-field dependence of $\mathrm{J}$ modulation in two-dimensional NMR spectra. J. Magn. Reson. 124:512-515.

Tjandra, N., Grzesiek, S., and Bax, A. 1996. Magnetic field dependance of nitrogen-proton J splittings in ${ }^{15} \mathrm{~N}$-enriched human ubiquitin resulting from relaxation interference and residual dipolar coupling. J. Am. Chem. Soc. 118:6264-6272.

Tjandra, N., Omichinski, J.G., Gronenborn, A.M., Clore, G.M., and Bax, A. 1997. Use of dipolar ${ }^{1} \mathrm{H}-{ }^{15} \mathrm{~N}$ and ${ }^{1} \mathrm{H}^{13} \mathrm{C}$ couplings in the structure determination of magnetically oriented macromolecules in solution. Nature Struct. Biol. 4:732-738.
Tolbert, T.J. and Williamson, J.R. 1996. Preparation of specifically deuterated RNA for NMR studies using a combination of chemical and enzymatic synthesis. J. Am. Chem. Soc. 118:7929-7940.

Varani, G. and Tinoco, J.I. 1991. RNA structure and NMR spectroscopy. Q. Rev. Biophys. 24:479532.

Varani, G., Aboul-ela, F., Allain, F., and Gubser, C.C. 1995 . Novel three-dimensional ${ }^{1} \mathrm{H}_{-}-{ }^{13} \mathrm{C}-{ }^{31} \mathrm{P}$ triple resonance experiments for sequential backbone correlations in nucleic acids. J. Biomol. NMR 5:315-320.

Varani, G., Aboul-ela, F., and Allain, F. H.-T. 1996. NMR investigation of RNA structure. Prog. Nucl. Magn. Reson. Spectrosc. 29:51-127.

Wijmenga, S.S. and van Buuren, B.N.M. 1998. The use of NMR methods for conformational studies of nucleic acids. Prog. Nucl. Magn. Reson. Spectrosc. 32:287-387.

Wijmenga, S.S., Heus, H.A., Leeuw, H.A.E., Hoppe, H., van der Graaf, M., and Hilbers, C.W. 1995. Sequential backbone assignment of uniformly ${ }^{13} \mathrm{C}$-labeled RNAs by a two-dimensional $\mathrm{P}(\mathrm{CC}) \mathrm{H}-\mathrm{TOCSY}$ triple resonance NMR experiment. J. Biomol. NMR 5:82-86.

Wöhnert, J., Ramachandran, R., Görlach, M., and Brown, L.R. 1999. Triple-resonance experiments for correlation of $\mathrm{H} 5$ and exchangeable pyrimidine base hydrogens in ${ }^{13} \mathrm{C},{ }^{15} \mathrm{~N}$-labeled RNA. J. Magn. Reson. 139:430-433.

Wüthrich, K. 1986. NMR of Proteins and Nucleic Acids. John Wiley \& Sons, New York.

Wüthrich, K. 1998. The second decade-into the third millenium. Nature Struct. Biol. 5:492-495.

Xu, J., Lapham, J., and Crothers, D.M. 1996. Determining RNA solution structure by segmental isotopic labeling and NMR: Application to Caenorhabditis elegans spliced leader RNA 1. Proc. Natl. Acad. Sci. U.S.A. 93:44-48.

$\mathrm{Xu}, \mathrm{X}$. -P., Chiu, W.-L.A.K., and Au-Yeung, S.C.F. 1998. Chemical shift and structure relationship in nucleic acids: Correlation of backbone torsion angles $\gamma$ and $\alpha$ with $13 \mathrm{C}$ chemical shifts. J. Am. Chem. Soc. 120:4230-4231.

Ye, X., Kumar, R.A., and Patel, D.J. 1995. Molecular recognition in the bovine immunodeficiency virus tat peptide TAR RNA complex. Chem. Biol. 2:827-840.

Ye, X., Gorin, A., Ellington, A.D., and Patel, D.J. 1996. Deep penetration of an a-helix into a widened RNA major groove in the HIV-1 rev peptide-RNA aptamer complex. Nature Struct. Biol. 3:1026-1033.

Zhang, X., Gaffney, B.L., and Jones, R.A. $1998 .{ }^{15} \mathrm{~N}$ NMR of RNA fragments containing specifically labeled tandem GA pairs. J. Am. Chem. Soc. 120:6625-6626.
Biophysical Analysis of Nucleic Acids

7.7.29

Supplement 2 
Contributed by M. Hennig

and J.R. Williamson

The Scripps Research Institute

La Jolla, California

\section{A.S. Brodsky}

Dana-Farber Cancer Institute

Boston, Massachusetts

J.L. Battiste

Harvard Medical School

Boston, Massachusetts

We thank all the scientists with whom we have interacted and have enjoyed fruitful discussions in helping us learn and think about RNA NMR. This work was supported by a grant from the NIH (GM-47467). M. Hennig acknowledges support of the Human Frontier Science Program. 